\title{
CROSSING CORRIDORS: WILDLIFE USE OF JUMPOUTS AND \\ UNDERCROSSINGS ALONG A HIGHWAY WITH \\ WILDLIFE EXCLUSION FENCING
}

\author{
A Thesis \\ presented to \\ the Faculty of California Polytechnic State University, \\ San Luis Obispo
}

\author{
In Partial Fulfillment \\ of the Requirements for the Degree \\ Master of Science in Biology
}

by

Alex Joseph Jensen

August 2018 
(C) 2018

Alex Joseph Jensen

ALL RIGHTS RESERVED 
TITLE:

AUTHOR:

DATE SUBMITTED:

COMMITTEE CHAIR:

COMMITTEE MEMBER:

COMMITTEE MEMBER:

COMMITTEE MEMBER:
Crossing Corridors: Wildlife use of

jumpouts and undercrossings along a

highway with wildlife exclusion fencing

Alex Joseph Jensen

August 2018

John Perrine, Ph.D.

Associate Professor of Biological Sciences

Clinton Francis, $\mathrm{PhD}$

Assistant Professor of Biological Sciences

Andrew Schaffner, PhD

Professor of Statistics

Anthony Giordano, $\mathrm{PhD}$

Executive Director \& President of

S.P.E.C.I.E.S 


\begin{abstract}
Crossing Corridors: Wildlife use of jumpouts and undercrossings along a highway with wildlife exclusion fencing
\end{abstract}

Alex Joseph Jensen

Roads pose two central problems for wildlife: wildlife-vehicle collisions (WVCs) and habitat fragmentation. Wildlife exclusion fencing can reduce WVCs but can exacerbate fragmentation. In Chapter 1, I summarize the relevant studies addressing these two problems, with a focus on large mammals in North America. Chapters 2 and 3 summarize field assessments of technologies to reduce WVCs and maintain connectivity, specifically jumpout ramps and underpasses, along Highway 101 near San Luis Obispo, CA. In a fenced highway, some animals inevitably breach the fence and become trapped, which increases the risk of a wildlife-vehicle collision. Earthen escape ramps, or "jumpouts", can allow the trapped animal to escape the highway corridor. Few studies have quantified wildlife use of jumpouts, and none for $>2$ years. We used wildlife cameras to quantify wildlife use of 4 jumpouts from 2012-2017. Mule deer were $88 \%$ percent of our detections and jumped out $20 \%$ of the time. After accounting for pseudoreplication, $33 \%$ of the events were independent events, and 2 groups of deer accounted for $41 \%$ of all detections at the top of the jumpout. Female deer were $86 \%$ of the detections and were much more likely than males to return to the jumpout multiple times. This is the first study to document use of jumpouts for more than 3 years, the first to account for pseudoreplication, and the first to quantify differences in jumpout use between male and female mule deer. We recommend a jumpout height between $1.75 \mathrm{~m}-2 \mathrm{~m}$ for mule deer to increase the jumpout success rate. Chapter 3 addresses factors that may affect the use of undercrossings by mule deer and other wildlife. Wildlife crossings combined with 
wildlife exclusion fencing have been shown to be the most effective method to reduce wildlife-vehicle collisions while maintaining ecological connectivity. Although several studies have quantified wildlife use of undercrossings, very few have exceeded 24 months, and the factors affecting carnivores use of the undercrossings remain unclear. We quantified mule deer, black bear, mountain lion, and bobcat use of 11 undercrossings along Highway 101 near San Luis Obispo, California from 2012-2017. We constructed zero-inflated Poisson general linear models on the monthly activity of our focal species using underpass dimensionality, distance to cover, substrate, human activity, and location relative to the wildlife exclusion fence as predictor variables. We accounted for temporal variation, as well as spatial variation by quantifying the landscape resistance near each undercrossing. We found that deer almost exclusively used the larger underpasses whereas the carnivores were considerably less selective. Bears used undercrossings more that were within the wildlife exclusion fence, whereas mountain lion activity was higher outside the wildlife exclusion fence. Bobcat activity was highest and most widespread, and was negatively associated with distance to cover. Regional connectivity is most important for bear and mountain lion, and the surrounding habitat may be the most important predictor for their use of undercrossings. We recommend placing GPS collars on our focal species to more clearly document fine-scale habitat selection near the highway. 


\section{ACKNOWLEDGMENTS}

I would like to thank our collaborators at California Department of Transportation, Nancy Siepel and Morgan Robertson, for their field assistance and flexibility in taking me on as a volunteer. I appreciate Doug Brewster's technical expertise in helping set up our cameras in the undercrossings underneath Highway 101. I am grateful for the HOURS of time Cal Poly and Allan Hancock undergraduates devoted to field work and entering data, notably Sofia Carrillo, Gennesee Garcia, Maddie Stukan, and Mason Dubois. A big shout out to the staff in the Biological Sciences department: Kristin Reeves, Ellen Calcagno, and Melanie Gutierrez. I appreciate my committee for their guidance; thank you to Andrew Schaffner for his statistical expertise, and Clinton Francis and Anthony Giordano for their valuable feedback and advice. Thank you most of all to my advisor, Dr. John Perrine. He has helped me become a better scientist, as well as a better writer. I appreciate the time and energy he invested in me during this process. 


\section{TABLE OF CONTENTS}

Page

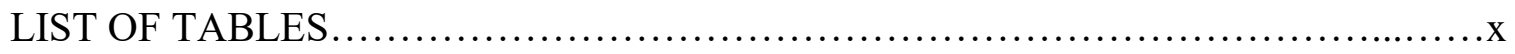

LIST OF FIGURES..................................................................

\section{CHAPTER}

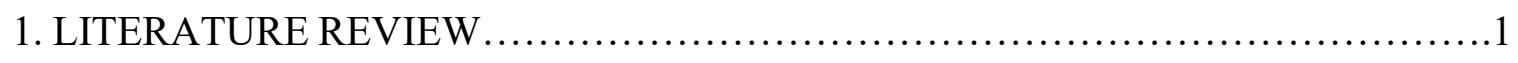

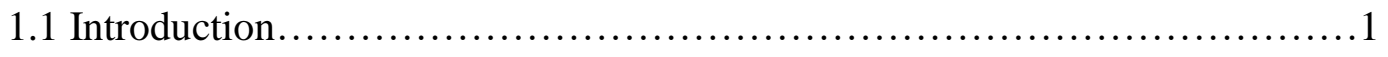

1.2 Part 1: How Roads Affect Wildlife.........................................2

1.2.a Direct effects: Wildlife-Vehicle Collisions...........................

1.2.a.i Temporal variation..................................... 4

1.2.a.ii Human health and economics..........................6

1.2.b Indirect effects............................................ 6

1.3 Part 2: Mitigation..................................................... 10

1.3.a Wildlife exclusion fencing ....................................10

1.3.b Jumpouts................................................... 11

1.3.c Wildlife crossings.............................................. 14

1.3.c.i Dimensionality...................................... 16

1.3.c.ii Human dimensionality...................................17

1.3.c.iii Temporal and spatial variation..........................18

1.3.c.iv Adaptation time......................................19

1.3.c.v Community interactions................................19

1.3.c.vi Other factors........................................20

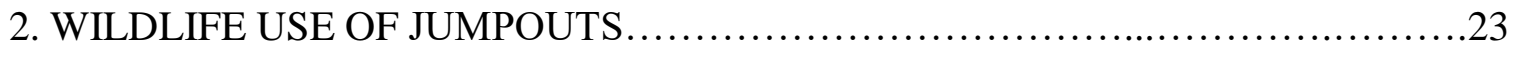




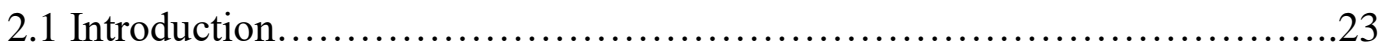

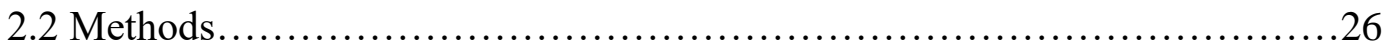

2.2.a Study site............................................. 26

2.2.b Data collection............................................... 27

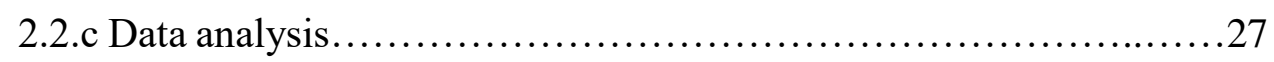

2.3 Results..........................................................29

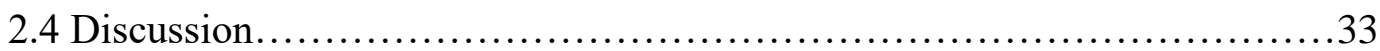

2.4.a Group dynamics.......................................... 37

2.4.b Deer behavior.............................................. 38

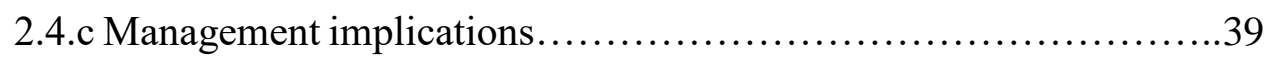

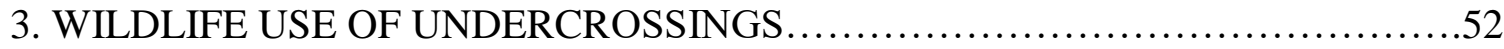

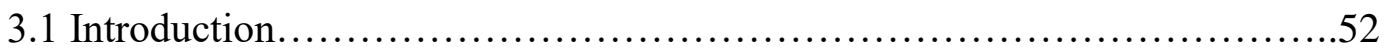

3.2 Methods......................................................... 55

3.2.a Study site..............................................55

3.2.b Data collection............................................56

3.2.c Data analysis.............................................57

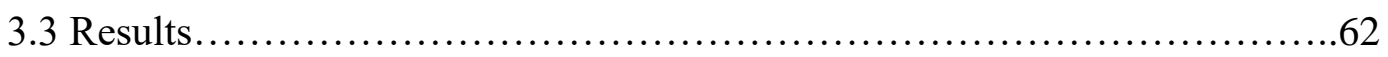

3.3.a Landscape resistance...................................63

3.3.b Dimensionality.......................................6 63

3.3.c Distance to cover and substrate..............................64

3.3.d Fencing and human activity ...............................64

3.4 Discussion..................................................6 65

3.4.a Deer.......................................................65 
3.4.b Bear......

3.4.c Mountain lion...............................................69

3.4.d Bobcat.................................................71

3.4.e Next steps.............................................. 72

3.4.f Management implications...................................... 72

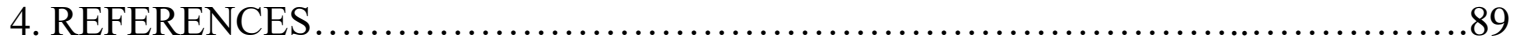




\section{LIST OF TABLES}

Table

Page

Table 2.1: Camera performance across all 4 sites. "Day active only" indicates that the camera was not functional at night due to flash failure.

Table 2.2: The number (\%) of detection events per species by site. These numbers are irrespective of group size...

Table 2.3: Number (\%) of deer detection events by site. 4 different outcomes relative to the wildlife exclusion fence: II means approached from inside and stayed inside (did not jump out), IO means approached from inside and went outside (jumped out), OO means approached the jumpout from outside and stayed outside, I? means the event started on the inside (on top of the jumpout ramp) but the outcome was ambiguous, and OI means approached the jumpout from outside and jumped in.

Table 2.4: Outcomes of events that began at the top of the jumpout ramp for male and female deer. II means approached from inside and stayed inside (did not jump out), and IO means approached from inside and went outside (jumped out). Detections during the months of February, March, and April were removed

Table 2.5: Initial outcomes and jumpout ratios of 10 groups of deer detected multiple times. Groups A-F are composed of females and juveniles that were detected at least 10 times, groups G-J have a male deer in the group and were detected multiple times. IO indicates events where the group successfully jumped out.

Table 3.1: Total survey effort for each site, including monitoring time frame.

Table 3.2a: Undercrossing attributes: dimensionality and distance to cover. Openness is (width*height)/length. SB indicates the undercrossing entrance on the southbound side of the highway, NB indicates the northbound side, and Avg. is the average of the two.

Table 3.2b: Undercrossing landscape resistance, average number of human detections per month, whether or not the undercrossing is within the wildlife exclusion fence zone, and the substrate within each undercrossing. Resistance values are calculated from Thorne and Huber (2011) and higher values indicate lower connectivity.

Table 3.3: Factor effects for bobcat, mountain lion, bear, and deer models with underpasses included. The response is the monthly count of detections of each focal species. Effect is the directionality of the factor on activity, $p$ value is whether or the effect was significant, and $\beta$ is the effect size for that factor. 
Bold values indicate significance at the 0.05 level. Effects and beta coefficients are not listed for multi-level categorical variables, year and season. For "within fence", a positive beta indicates more use outside the wildlife exclusion fence zone. For "substrate", a positive value indicates more use on concrete substrate.

Table 3.4: Factor effects for bobcat, mountain lion, and bear models with underpasses removed. The response is monthly count of each focal species. Effect is the directionality of the factor on activity, $p$ value is whether or the effect was significant, and the $\beta$ is the effect size for that factor. Effects and beta coefficient not listed for multi-level categorical variables, year and season. Bold values indicate significance at the 0.05 level. For "within fence", a positive beta indicates more use outside the wildlife exclusion fence zone. For "substrate", a positive value indicates more use on concrete substrate. Deer were not included because their activity was clearly associated with the underpasses.

Table 3.5a: Count and activity of bobcat and mountain lion at each site. Count is the number of detection events for a given species, irrespective of group size. Activity is the count divided by the total survey days. "Act*30" is activity multiplied by 30 to estimate the number of monthly detections at each site. "_" indicates zero activity for clarity.

Table 3.5b: Count and activity of deer and black bear at each site. Count is the number of detection events for a given species, irrespective of group size. "act." is the count divided by the total survey days. "act*30" is activity multiplied by 30 to estimate the number of monthly detections at each site. "_" indicates zero activity for clarity. 


\section{LIST OF FIGURES}

Figure

Page

Figure 1.1: Jumpout ramp along Highway 101 in San Luis Obispo County, California (TjCk-N site).

Figure 2.1: Jumpout ramp along Highway 101 in San Luis Obispo County, California (TjCk-N site).

Figure 2.2: Four jumpouts along Highway 101 between San Luis Obispo and

Atascadero, California. The wildlife exclusion fence is $4 \mathrm{~km}$ long...

Figure 2.3: Deer activity at all 4 jumpouts irrespective of group size.

Figure 2.4: Comparison of male and female deer with the months of February-April removed. Total detections only includes events that started at the top of the ramp. Red bars indicate how many groups/individuals jumped out, and green bars indicate how many detections were unique groups/individuals.

Figure 2.5: Male deer about to jump out at the Hwy58-S site. .50

Figure 2.6: A doe and yearling fawn pair (Group B) bedded down the Hwy58-S jumpout.

Figure 3.1: Location of undercrossings along a $19.3 \mathrm{~km}$ section of Highway 101 between San Luis Obispo and Atascadero, California, USA. The wildlife exclusion fence is $4 \mathrm{~km}$ long.

Figure 3.2: Covariance matrix between height, length, width, and openness. Height and width were highly $(>0.7)$ correlated with openness, so height and width were not included in modeling. Open indicates the factor "OPENNESS".

Figure 3.3: Monthly count of deer detections at each site, irrespective of group

size. Deer almost exclusively used the two underpasses (RR and SM). N=610....

Figure 3.4: Monthly count of bear at each site, irrespective of group size. $\mathrm{N}=142 \ldots \ldots . .84$

Figure 3.5: Monthly count of mountain lion at each site, irrespective of group size.

$\mathrm{N}=32$. . .

Figure 3.6: Monthly count of bobcat at each site, irrespective of group size.

$\mathrm{N}=1231$.

Figure 3.7: Monthly count of human at each site, irrespective of group size.

$\mathrm{N}=188$. 
Figure 3.8: Focal species activity at each site. Bars are the average monthly count divided by 30 to give an estimate for daily activity. RR and SM are both

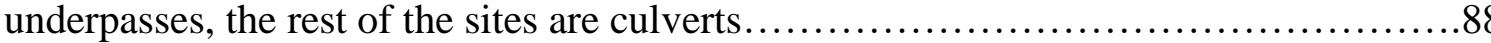




\section{Chapter 1}

\section{LITERATURE REVIEW: HOW ROADS AFFECT WILDLIFE AND TWO WAYS HUMANS HAVE TRIED TO MITIGATE THOSE EFFECTS}

Man holds the awesome power to alter his environment and the occasional ability to manage the results. -Michael Puglisi (1974)

\section{INTRODUCTION}

Habitat fragmentation is one of the most harmful and ubiquitous consequences of human development, and in the long run, it may be just as disastrous as direct habitat destruction (Harris and Scheck 1991). Fragmentation is harmful because an individual may not be able meet all of its biological needs (i.e., finding food and/or mates) within a single patch in a fragmented habitat. Moving between patches exposes individuals to increased risks, assuming they are able to move between patches at all. At the population level, fragmented habitat has a higher proportion of lower quality habitat (edge effects), impedes recolonization and dispersal, while increasing the chances of inbreeding within populations (Spencer et al. 2010, Clevenger and Huijser 2011).

While some sources of fragmentation are natural (e.g., rivers and mountain ranges), anthropogenic fragmentation is a major conservation concern. The effects of human development are wide-ranging and extensive, but none have modified the natural landscape like the construction and maintenance of roads (Noss and Cooperrider 1994). Roads are one of the most potent agents of ecological destruction worldwide, affecting habitat structure and wildlife populations (Forman and Alexander 1998). In 1997, roads covered about $1.1 \%$ of U.S. land area, with $0.6 \%$ being the actual road and $0.5 \%$ being the roadside (Forman et al. 2003). 
Although roads physically cover a significant amount of land, not all roads have the same ecological effects. With some exceptions (such as roadkills; see below), traffic volume and ecological effect are positively correlated. While $80 \%$ of the roads in the U.S. are considered "low volume" (serving <400 vehicles/day; Forman et al. 2003), major roads such as highways and freeways can pose significant barriers to wildlife movement (Lee et al. 2012, Riley et al. 2006). Arterial roads (mainly for long distance travel) and highways have been focal in regard to their ecological impacts because they frequently cut through natural areas and serve $72 \%$ of all U.S. road travel while consisting of only $11 \%$ of the U.S. road system (Forman et al. 2003).

Part I of this literature review breaks down the direct and indirect effects that roads have on wildlife, focusing on wildlife-vehicle collisions and habitat fragmentation. Part II summarizes ways that road ecologists have mitigated for these effects, with a focus on jumpouts and undercrossings. Included in Part II are gaps in knowledge where further research is needed.

\section{PART I: HOW ROADS AFFECT WILDLIFE}

The ecological effects of roads are diverse but generally fall into 4 categories: 1) vehicle-wildlife collision mortality; 2) loss of habitat due to the physical footprint of the road; 3) reduced habitat quality adjacent to roads (Forman and Alexander 1998, Beckmann et al. 2010); 4) habitat fragmentation due to roads' barrier effects. Factors 1 and 2 are physical effects that are often easier to quantify than 3 and 4 . 


\section{Direct effects: Wildlife-Vehicle Collisions}

Wildlife-vehicle collisions (hereafter WVCs) and resulting animal mortalities ("roadkill") are the most familiar and socially relevant consequences of interactions between roads and wildlife. In the United States, WVCs with mammals, birds, and reptiles were recorded as early as 1924 (Stoner 1925). As vehicular traffic has increased, the number of WVCs has increased as well. In Pennsylvania from 1969-1982, officials reported 313,338 collisions with white-tailed deer (Odocoileus virgnianus) across all highways (Bashore et al. 1985). In the entire United States from 1990-2004 WVCs increased by $50 \%$, while deer (Odocoileus spp.) accounted for $77 \%$ of the increase (Huijser et al. 2007) and approximately 5\% of all reported collisions (Clevenger and Huijser 2011). Clevenger and Huijser (2011) attributed this increase to more "vehicle miles traveled" and general deer population growth. Deer are often involved in potentially fatal WVCs due to a combination of their large size, ubiquity across the landscape, and the dazzling effect of headlights.

Forman and Alexander (1998) estimated that one million vertebrates are killed on United States roads every day. Most of these deaths are rodents and birds, which reproduce faster than the rate they are killed by vehicles. Nonetheless, WVCs can be a significant mortality source for those species with relatively low population densities, which are typically large bodied, and often listed under the Endangered Species Act. Before 1991, WVCs accounted for $\sim 10 \%$ of Florida panther (Puma concolor coryi) mortality, and $\sim 16 \%$ of key deer mortality (Odocoileus virginianus clavium; Forman and Alexander 1998). By 1991, wildlife crossings were constructed to increase the highway's permeability, which significantly reduced the number of WVCs with these species. In 
Tasmania, WVCs became a significant source of mortality for Eastern quolls (Dasyurus viverrinus) and Tasmanian devils (Sarcophilus harrisii) after a road was widened and traffic speed allowed to increase (Jones 2000). Alarmingly, it has been estimated that only half of all large mammal collisions and virtually none of the WVCs with smaller species are reported (Garbutt 2009).

There is variation across and within species when considering likelihood of a WVC. Metapopulation theory suggests that more mobile species would better be able to adapt to habitat loss and fragmentation. Yet when barriers within the habitat matrix are deadly, more mobile species may actually be more vulnerable to habitat loss (Clevenger and Huijser 2011). Generally, roadkill is nonspecific in regard to age, sex, and condition of individuals within a species (Bangs et al. 1989). A probable exception is mountain lions (Puma concolor); roads are probably the largest source of mortality for dispersing subadult males between 10 and 33 months (Beier et al. 1995, Hemker et al 1984, Maehr et al. 1991). Young dispersers are not only inexperienced, but are generally traveling through unfamiliar territory, and thus are more likely to be struck by a vehicle.

\section{Temporal Variation}

It may be intuitive that WVCs vary in space, but they also vary in time. Season seems to be an important predictor for carnivores. Small and medium sized carnivore use of culverts under roads in Portugal was highest in the spring (Grilo et al. 2008) and bobcat (Lynx rufus) vehicle mortality in Southern California was highest during the breeding season (September-March; Jennings 2013). Given that deer (Odocoileus spp.) are involved in most serious WVCs, several groups have documented how seasonal variation in their behavior might affect the rate of WVCs. Most evidence points towards 
deer collisions being highest during the breeding season: October - December. In Virginia, 52\% of the annual collisions with deer from 2013-2015 occurred in October and November alone (Donaldson et al. 2015). Similarly, two-thirds of annual deer collisions in New York state occurred in October-December (New York Department of Motor Vehicles 2006). In some cases, there were spikes in deer-vehicle collisions during both fall and spring. In Pennsylvania, there were significantly more deer collisions in the spring and fall of 1979 and 1980 than the rest of the year (Puglisi et al. 1974, Bashore et al. 1985). Puglisi et al. (1974) attributed these spikes to increased agitation due to hunting activity (in fall) and increased grazing (new vegetation next to highways) and post winter dispersal (in spring). WVC rate may also depend on variation in seasonal vehicular traffic as well. For example, roadkills in Alberta, Canada were highest in the summer months, due to higher animal activity and vehicular traffic levels (Clevenger et al. 2003). The highest rates of WVCs are during the fall, although there can be spikes during other times of the year depending on the focal species and human activity.

Animal activity patterns also vary throughout the day, which could lead to varying collision risk. Some species exhibit crepuscular activity (most active during the hours around dawn and dusk), which combined with intermediate traffic levels during those times could lead to higher rates of collision. In Central California, Snyder (2014) found that collision potential was highest for mule deer (Odocoileus hemionus) during the morning and evening, and highest for mesocarnivores in the evening during most of the year, and highest in the morning during the summer. In Colorado, Siemers et al. (2015) also found that mule deer activity as highest during the crepuscular time periods. Lastly, 
collision risk may go up during the night because human detection ability is probably worse at night.

\section{Human health and economics}

WVCs involving large mammals can cause substantial vehicle damage as well as human injury or death. Every year in the United States deer (Odocoileus spp.) cause 150200 human deaths, more than 29,000 human injuries, and \$1.1 billion in personal property damage (Stull et al. 2011, Mastro et al. 2008). Several studies have quantified the economic cost of WVCs. As calculated by the National Highway Traffic Administration (Blincoe et al. 2002) a single human traffic fatality or serious injury has lifetime economic costs of around $\$ 1,000,000$. Huijser et al. (2009) estimated that the average collision with a deer and a vehicle costs society $\$ 6,671$, and argued that that measures to mitigate WVCs make economic sense not even considering the benefits to conservation.

\section{Indirect Effects}

The fact that roads cover $1.1 \%$ of the United States does not take into account the numerous effects that reach beyond the physical footprint of roadways. Forman (2000) estimated that roads ecologically affect $15-20 \%$ percent of the land area in the United States, which is the same as the combined area of Alaska (15\%) and California (5\%). Roads can have significant barrier (Poessel et al. 2014) or filtration (Clevenger and Waltho 2005) effects on the movement of wildlife. When roads are barriers, they can divide populations by physically stopping animals from crossing the road. Roads act like filters when they are permeable to some species yet not others, or reduce movement rates 
across the landscape. In recent decades, traffic noise has been found to have a negative impact on some species (Shilling and Waetjen 2012). Birds may be most impacted by traffic noise, as it can interfere with vocal signaling (Forman and Deblinger 2000). Roads can also facilitate the spread of invasive species, promote erosion, and pollute nearby land and waterways (Forman et al. 2003).

Carnivores are often more impacted by habitat fragmentation than other species because of their relatively large ranges, low population density, and conflicts with (and persecution by) humans (Crooks 2002). Thus large and medium sized carnivores have been focal in fragmentation research, and several studies have documented carnivores actively avoiding areas with roads. In Utah and Arizona, mountain lion home ranges tended to be in areas with lower densities of improved dirt and paved roads, suggesting either they either tended to avoid these types of roads or they do not tend to be built in prime mountain lion habitat (Van Dyke et al. 1986). In the Netherlands, high road density was explicitly linked to European badger (Meles meles) population declines, suggesting that badgers avoided disturbed habitat and vehicle collisions contributed to the decline (Van der Zee et al. 1992). In Southern California, bobcat home ranges were larger in areas that included roads, suggesting that these areas were lower quality habitat (Riley et al. 2003).

Even within carnivores, there is variation in road avoidance among and within species. Mesocarnivores (such as bobcats) exhibit moderate sensitivity to fragmentation, and therefore may be the best ecological indicators of habitat connectivity because they can tolerate some levels of disturbance without disappearing from the landscape (Poessel et al. 2014). In Montana, wolverine (Gulo gulo) home ranges were not impacted by the 
presence of highways (Hornocker and Hash 1981), and in Florida, female Florida panthers were more road-averse than males (Cramer and Portier 2001). Body size may be an important predictor of extinction probability for carnivore species within a fragmented ecosystem (Brown 1986, Belovsky 1987). In addition to body size, Crooks (2002) found that sensitivity to fragmentation was also dependent on the species' response to urban development. Crooks conducted carnivore track surveys in coastal Southern California on different sized patches of land, and found that mountain lions tended to disappear from smaller and more isolated patches, coyotes (Canis latrans) were hardly affected, and the bobcat response was somewhere in the middle. Therefore, while body size is probably an important predictor, some species are less sensitive to anthropogenic fragmentation than others.

Another reason carnivores have been focal in fragmentation research is their "keystone" role in ecosystems (Crooks and Soulé 1999), as the presence of top predators such as mountain lions is often an indicator of ecological integrity (Thorne et al. 2002). Top predators play important "top-down" roles, by controlling the quantity, activity, and distribution of their prey species (Ripple et al. 2014). When habitat becomes too fragmented for top predators, subordinate "mesopredators" can undergo "ecological release" and increase in quantity and activity (Crooks and Soulé 1999), which can have cascading effects down trophic levels. This is evidenced by the increase of raccoons (Procyon lotor; and deer) in areas where their predators have been removed (Thorne et al. 2002).

At a more local scale, road avoidance patterns can also depend on traffic volume. In Arizona, elk (Cervus canadensis) were more likely to be near the highway when traffic 
volumes were low ( 100 vehicles/hr; Gagnon et al. 2007), and in Banff National Park in Canada, grizzly bears (Ursus arctos) tended to be closer to roads with lower traffic volumes (Chruszcz et al 2003). Large mammals avoid higher traffic volumes for a couple of reasons, primarily traffic noise. Noise effects can extend several hundred meters to nearly $3 \mathrm{~km}$ in a variety of California landscapes (Shilling and Waetjen 2012). Roads that have a combination of intermediate traffic volume traveling at high speeds may have the highest rates of WVCs. Low traffic volume probably allows animals to cross safely most of the time, while animals simply avoid the road entirely when traffic volumes become too high.

Roads can have complicated secondary ecological effects. The area immediately adjacent to the road (the "right of way") can serve as important habitat and even facilitate movement for some species. In Pennsylvania, significant numbers of white-tailed deer (Odocoileus virginianus) crossed intact interstate fences to gain access to vegetation on highway margins when food was limited in the forest (Bashore et al. 1985). The population density of small mammals is sometimes positively associated with roads, possibly because of the relatively higher negative effects of roads on their predators (Rytwinski unpublished). Lastly, roadkill can be a fatal attraction for scavengers that are then at risk of being struck by a vehicle as well.

In summary, roads pose two central problems for wildlife: 1) death due to being struck by vehicles, which can be a significant source of mortality for low density and/or endangered species and 2) reduced habitat size from roads acting as barriers or animals behaviorally avoiding roads. Part 2 will summarize ways to mitigate these effects, with a 
focus on jumpout ramps as a relatively novel method to reduce WVCs, and

undercrossings as the leading method to provide safe passage for wildlife across roads.

\section{Part 2: MITIGATION}

\section{Wildlife exclusion fencing}

Transportation planners are increasingly interested in ways to mitigate the costs of WVCs and reduced connectivity for wildlife. Wildlife exclusion fencing has been found to be the most effective way to reduce WVCs. In a 2015 review, Huisjer et al. found that well designed, implemented, and maintained wildlife exclusion fencing can reduce collisions with large animals by 80-100\%. A 2016 meta-analysis by Rytwinski et al. showed that fences reduce WVCs by $54 \%$, with or without associated crossing structures. Other studies found that wildlife fencing is the most effective nonlethal method for reducing collisions with deer specifically (Falk et al. 1978, Clevenger and Huijser 2011).

Despite these advantages, fencing can present additional problems. Although WVC rate often decreases within the fenced zone, WVCs can be clustered at fence ends (Clevenger et al. 2001). Further, in areas with development, gaps in fences are often necessary to accommodate side roads leading to homes or utility infrastructure. Gates are a solution for low volume side roads, although they can be left open. For higher volume roads, various types of wildlife guards have been tested, and seem to be more effective for ungulates (deer and other hooved mammals) than other taxa. For example, in Montana, wildlife guards (in this case - essentially cattle guards) were found to be $85 \%$ effective at deterring deer and 33-55\% effective at deterring black bear (Ursus americanus) and coyote (Allen et al. 2013). Electrified mats ("Electro-mats") are an 
emerging technology designed to also exclude plantigrade animals (e.g., bears) and other species that easily cross traditional wildlife guards (Perrine 2015). Another potential problem is prey entrapment; there is anecdotal evidence that reported an instance where wildlife fencing blocked big horn sheep (Ovis canadensis) from escaping from predators (Huisjer et al. 2015). Lastly, cost may be a factor, wildlife fencing is expensive. However, Shilling and Waetjen (2015) argued that the savings in lives, injury, and property damage from WVCs outweigh the cost.

\section{Jumpouts}

The goal of wildlife exclusion fencing is to significantly reduce the number of animals on the highway, but complete elimination is impractical. Animals will enter the fenced zone through side roads, fence ends, or gaps. This is dangerous because the animal is now trapped between the road and the fence, increasing the probability of a WVC. There is evidence that ungulates usually travel parallel to roads before attempting to cross (Puglisi et al. 1974, Bashore et al. 1985), so many fencing projects also include lateral escape measures. One-way gates are one method primarily designed for ungulates. Passive oneway gates allow ungulates to "push" open the gate from the inside but not the outside, while active one-way gates can either be opened by a patrolling wildlife manager or triggered by a sensor activated by an animal (Huijser et al. 2015). These one-way gates are generally not effective for medium or small animals, so Kruidering et al. (2005) designed a smaller escape gate for the European badger (Meles meles), which works like a one-way "doggie door". 
A newer solution to animals being trapped on the highway side of the fence is earthen escape ramps, or "jumpouts". Jumpouts are sloped mounds of earth that angle up to near the height of the fence, then abruptly drop off, essentially becoming a continuation of the fence on the non-highway side (Figure 1.1). They are sometimes set back from the fence a few meters and can have auxiliary fencing that guides animals towards them. Jumpouts have been installed in several places across the United States, but only a few groups have monitored them, and none >2 years. Bissonette and Hammer (2000) found $1.5 \mathrm{~m}$ high jumpouts to be 8-11 times more effective than one-way gates for deer. Clevenger et al. (2002) reported use of jumpouts by deer, elk, and coyote, although they documented only 32 detections in 33 months. In Arizona, bighorn sheep jumped out 96\% (332/337) of the time when detected at the top of the ramp (Gagnon et al. 2013). Huijser et al. (2013) reported differences between two deer species using 1.7-2.4 m high jumpouts; $25-60 \%$ of the mule deer used the jumpouts, but white-tailed deer hardly used them at all. In Colorado, the addition of 11 jumpouts significantly reduced the number of mule deer collisions per mile per year (Siemers et al. 2015). Before installation, there were 1.94 collisions/mile/year, which dropped to 1.53 after installing 3 jumpouts, and to 1.12 after 5 more were installed. They also documented 27 reversals (jumping over the wall and into the right-of-way) out of 2,965 visits across the 11 jumpouts. Jumpouts seem to be the most effective and efficient lateral escape measure, although only a few studies have quantified their success. All of the studies have focused on ungulates, with varying jump out success rates. However, none of these studies have marked individual animals so it is impossible to know how many individuals are returning to the same jumpout more 
than once, which means that these rates are not based on true replicates, but instead “pseudoreplicates” (Hurlbert 1984).

Ideal jumpout height is not established, and may very well be species dependent. This is a critical part of the design because the height of the jumpout is probably the main determining factor when animals are deciding whether to jumpout (at lease the first time they do so). The jumpout must be high enough to discourage use to enter the highway corridor, yet low enough that animals are willing to use it. The Arizona Department of Transportation (2013) recommended a height of 1.7-1.8m (any lower and elk can reverse the ramp), while Huijser et al. (2015) suggested jumpouts between 1.5 and $2.1 \mathrm{~m}$ high appear to function best for mule deer, elk, and bighorn sheep.

Factors other than height also likely affect wildlife use of jumpouts. In Colorado, distance to cover from the landing area was negatively correlated with mule deer jumpout success (Siemers et al. 2015). They recommend the landing area, as well as the surrounding 5-10 meters, be free from shrubs and other cover. Other important considerations are the quantity and spacing of the jumpouts. The Arizona Department of Transportation (2013) recommends a jumpout every $800 \mathrm{~m}$ on both sides of the road, while others have recommended one every 400m (Huijser et al. 2015). There may not be a universal ideal spacing between jumpouts, but placement may be most effective in areas where animals are most likely to enter the road corridor (i.e.,, near fence ends and access roads).

We know wildlife use jumpouts to escape the highway corridor, but jumpout success has varied in the limited number of studies that have been done. In order to obtain a true jumpout rate, psuedoreplication needs to be accounted for by marking 
individual animals. Jumpout success rate is probably principally determined by the height of the jumpout wall, and more research is needed to determine the ideal height for different species, as well as what other factors are important in determining jumpout success.

\section{Wildlife crossings}

Although fencing has been shown to decrease WVCs (Falk et al. 1978, Clevenger and Huijser 2011), fencing alone surely compounds the fragmentation effect of roads. Therefore, fencing can be used to funnel animals towards suitable crossing structures (Huijser et al. 2015). Fencing combined with wildlife crossings has been shown to be the most effective overall strategy for reducing WVCs while maintaining ecological connectivity (Loberger et al. 2013). The fence should lead wildlife to the crossing structure (Glista et al. 2009), which often entails invaginating the fence line towards the road. McCollister and Van Manen (2010) found that WVCs (primarily white-tailed deer) within a fenced zone were lowest near underpasses and increased with distance from the underpasses. Donaldson et al. (2015) cited several other studies and found that crossings combined with fencing reduced WVCs by more than $80 \%$. For example, in Florida, a culvert system integrated with a barrier wall reduced wildlife road mortality by $93.5 \%$ (Dodd et al. 2004). From a connectivity perspective, elk did not exhibit road avoidance behavior in sections of an Arizona highway with underpasses, yet did avoid the highway in sections without them (Gagnon et al. 2007). Ideally, managers should understand the relative impact of WVCs and reduced permeability when planning to mitigate their effects. 
Overcrossings and undercrossings have become the standard methods to increase a roads permeability. Compared to undercrossings, wildlife overcrossings are less common and often more expensive, yet seem to facilitate crossing by a broader suite of species. Sometimes referred to as "green bridges", wildlife overcrossings are typically planted with natural vegetation and are generally designed to provide large mammals with landscape level connectivity across the road (Glista et al. 2009). Wildlife overpasses are probably the most effective strategy to increase permeability for ungulates. In the Netherlands, red deer (Cervus elaphus) and wild boar (Sus scrofa) frequently used a wildlife overpass; the authors suggested that the 3 -fold increase in use by red deer over time was an indicator of adaptation (Van Wieren and Worm 2001).

Undercrossings are far more common, and typically fall into two categories: culverts and underpasses. Culverts are essentially tunnels originally designed to carry water under roads; they vary in size and makeup from $0.3 \mathrm{~m}$ diameter corrugated metal pipes to drive-through sized concrete boxes. Although drainage culverts can be retrofitted to promote use by wildlife (e.g., installing ledges that will remain dry; Meese et al. 2009), passages built for the sole purpose of facilitating animal use across the road are increasingly being incorporated into highway construction projects as well. Compared to culverts, underpasses are often taller, and much wider than culverts, thereby providing much less confined passage for wildlife. Not surprisingly, underpasses tend to be used by more species than culverts (Glista et al. 2009). Sometimes roads are built over waterways, which can provide a road-crossing opportunity for species traveling along the riparian corridor. 
The best crossing structures would facilitate movement of a wide range of species (Clevenger and Waltho 2000, Cramer and Bissonette 2005), particularly those that tend to be road averse, and/or of conservation concern. Managers are interested in why certain species decide to use or not use certain types of undercrossings. Below I summarize the literature on what factors are useful in predicting wildlife use of undercrossings.

\section{Dimensionality}

Of the many factors that can affect wildlife use of crossing structures, the most apparent is the structure's physical dimensions: height, width, and length. These factors can be combined into an "openness index":

$$
\text { height } \times \text { width } \div \text { length }=\text { Openness }
$$

where larger values indicate a more open undercrossing (Meese et al. 2009). Ungulates tend to use larger, more open undercrossings. A review by Mastro et al. (2008) found that Mule deer were more active in undercrossings with openness indexes greater than 0.8 , and tended to avoid anything less than 0.6. In Virginia, white-tailed deer activity was higher on the roadside near a box culvert compared to a bridge overpass, suggesting deer more readily used the overpass because they were less likely to be detected on the roadside near there (Donaldson et al. 2015). In Canada, deer, grizzly bear, grey wolves (Canis lupus), and elk also selected more open undercrossings (Clevenger and Waltho 2005). In contrast, Clevenger and Waltho (2000) found that ungulates selected smaller, less open undercrossings; yet more open culverts were significantly noisier, and closer to human habitation which likely confounded the results. However, in a recent report also from Canada, Clevenger and Barrueto (2014) again found that mule deer preferred more 
open crossing structures. Clevenger and Waltho (2005) suggested that structural attributes are the best predictors of large predator and prey species when there is not high human activity. Despite the ubiquity of the openness index in the literature, Clevenger and Huijser (2011) note that it is highly correlated with length, and therefore recommend using raw dimensions rather than the index.

Carnivores seem to more plastic in their use of undercrossings compared to ungulates. Clevenger and Waltho (2000) found that, with the exception of coyotes, all carnivores' activity was higher in small, less open culverts. In contrast, Grilo et al. (2008) found that carnivores preferred larger passages. In Banff National Park, Canada, bear and mountain lion activity was higher in longer and narrower underpasses (Clevenger and Waltho 2005), a pattern replicated for bear in a 17-year study (Clevenger and Barrueto 2014), but not found for mountain lion. At the very least carnivores do not seem to avoid smaller, less open undercrossings, and may actually select for them.

\section{Human activity}

Human activity can influence wildlife use of undercrossings. In Spain, ungulate tracks were never detected in any passages underneath a railway, likely due to human activity (Rodriguez et al. 1996). In a 17-year study in Canada, large mammals habituated to vehicular traffic over time, yet remained sensitive to human use of undercrossings (Clevenger and Barrueto 2014). Human activity had a slight negative impact on deer and mountain lion use, but no impact on bear use of crossing structures. In general, carnivores seem to be more disturbed than ungulates by human activity; even if undercrossings are placed in good habitat, too much human activity may preclude their use by carnivores (Clevenger and Waltho 2000). 


\section{Temporal and spatial variation}

The natural variation in landscape use by wildlife across spatial and temporal scales likely affects their use of undercrossings. Depending on the region, some species vary their movement rate significantly throughout the year. Crossing structures are typically used more in warmer times of the year (Sparks and Gates 2017), due to a general increase in activity during the warmer months. For example, in Canada, deer and mountain lion activity was highest in warmer months (Clevenger and Barrueto 2014).

Habitat suitability may be the strongest predictor of a particular species use of the culvert; if the culvert is in poor habitat, it is probably less likely to be used, and vice versa (Yanes et al. 1995, Clevenger and Waltho 2000). One way to model habitat suitability is based on vegetative community, topography, and human development density (including road density; Thorne and Huber 2011). In general, wildlife tend to use areas with flat slopes, and low topographic density (Alexander and Waters 2000). In Canada, mountain lions activity was higher in crossing structures with less vegetative cover in a $1 \mathrm{~km}$ radius around the culvert (Clevenger and Barrueto 2014). Mountain lions in particular are known to travel along streams that lead into undercrossings (Beier et al. 1995). In Southern California, bobcats and coyotes tended to use passages in areas surrounded by less human development (Ng et al. 2004). Andis et al. (2017) compared large mammal movement between arch-style underpasses and the surrounding habitat. They found that mule deer used the underpasses significantly more, while black bear and coyote were detected as expected based on movement through the surrounding habitat. Managing the surrounding habitat around undercrossings may be a cost-effective way to increase use by wildlife (Grilo et al. 2008). 
On a more local scale, $\mathrm{Ng}$ et al. (2004) found that habitat type within a 250m semicircle on either side of passage was important for predicting use by bobcats and coyotes. Grilo et al. (2008) also reported that surrounding habitat, vegetation height at crossing entrances, and distance to forest cover were important for some carnivores. In Canada, distance to cover was positively correlated with use by mountain lion, grizzly bear, elk, and deer (Clevenger and Waltho 2005). This pattern may be inversely true for small to mid-sized mammals that prefer the safety of cover (Rodriguez et al. 1996). Likewise, Beier et al. (1995) found that mountain lions used undercrossings with "ample woody cover".

\section{Adaptation time}

When wildlife crossing structures are installed or retrofitted, it may take some time for wildlife to adapt to the new infrastructure. Large mammals can take 5-6 years to adapt to crossing structures, although ungulates typically adapt faster than carnivores (Clevenger and Huijser 2011). However, monitoring studies average 17 months (Clevenger et al. 2009), rarely long enough to capture long term adaptation. To date, only one study examines long term adaptation: a 17-year study by Clevenger and Barrueto (2014), who found that mule deer use of crossing structures increased with time up to year 8 , then leveled off.

\section{Community interactions}

Little is known about how community interactions affect wildlife use of undercrossings, such as if competitors exhibit any avoidance of the same undercrossings, or whether prey species avoid undercrossings used by predators. In Florida, Foster and Humphrey (1995) suggest that deer avoided a particular underpass because it was frequently used by 
Florida panther, bobcat, and humans. Little et al. (2002) found little evidence that predators use undercrossings as prey traps - rather, most predatory events were opportunistic. Moreover, undercrossings that are used more by predator or prey may decouple predator-prey relationships, particularly if undercrossings can serve as prey refuges (Clevenger and Waltho 2005). In Canada, carnivores tended to use undercrossings close to drainage systems, while ungulates avoided them (Clevenger and Waltho 2000). Also in Canada, there were positive correlations between wolf $\&$ grizzly bear, and wolf \& deer (Clevenger and Barrueto 2014). The authors suggested that the former pairing indicated shared preference, while the latter may be an indication of predatory intentions.

\section{Other factors}

In an experiment on the effect of artificial light on underpass use, Columbia black-tailed deer (O.h. columbianus) were much more likely to use unlit sections of an underpass than sections lit with artificial lights (Bliss-Ketchum et al. 2016). Beier et al. (1995) reported a similar pattern: mountains lions tended to use undercrossings that lack artificial lighting. In Canada, bear used culverts that were farther away from water (Clevenger and Barrueto 2014). In this same study, distance to water, and tree cover within a 1-km radius were both found to no have no impact on deer crossing use. "Clarity of exit" (being able to see the exit from the culvert entrance) may be important for some species (Rosell et al., 1997, Knapp et al. 2004).

In summary, ungulates and carnivores seem to select for somewhat different undercrossings. Ungulates use larger, more open undercrossings more than smaller, less open ones, while carnivores (especially large ones) either are not as affected by 
dimensionality or select for smaller, less open undercrossings. The surrounding landscape probably plays a major role in determining how often different species will be near a particular undercrossing in the first place. Human activity likely negatively affects use of undercrossings by most species to some extent, albeit carnivores are probably more deterred than ungulates. More research is needed in how interspecific interactions are affecting wildlife use of undercrossings, as well as long term acclimation to retrofitted crossing structures. 


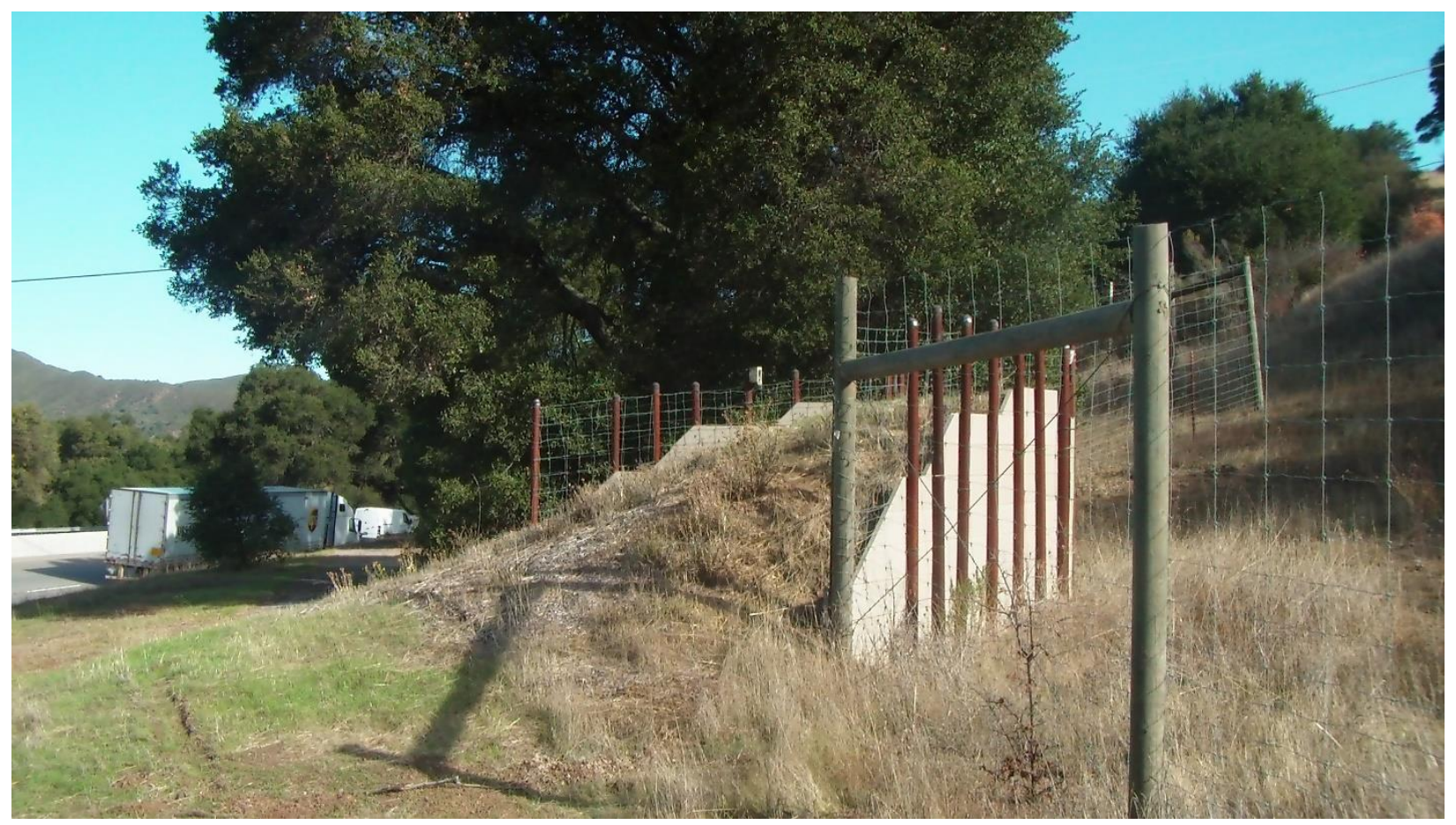

Figure 1.1: Jumpout ramp along Highway 101 in San Luis Obispo County, California (TjCk-N site). 


\section{CHAPTER 2}

\section{WILDLIFE USE OF JUMPOUTS ALONG A HIGHWAY WITH WILDLIFE EXCLUSION FENCING}

\section{INTRODUCTION}

Roads can pose serious problems for wildlife. At the ecological level, roads fragment habitat which can hinder dispersal and recolonization, increase the chance of inbreeding within populations, and decouple predator-prey dynamics (Clevenger and Huijser 2011, Spencer et al. 2010, Clevenger and Waltho 2005). At the population level, roads can cause significant mortality because wildlife-vehicle collisions (hereafter WVCs) often result in the death of the animal involved. An estimated 1,000,000 vertebrates are killed on United States roads every day (Forman and Alexander 1998). Most of these species are r-selected (like rodents and most birds), that reproduce fast enough for vehicle mortality to have marginal effects on their populations. However, WVCs can be a significant mortality source for species that are lower density across the landscape, typically large bodied, and sometimes listed under the Endangered Species Act. For example, WVCs accounted for $50 \%$ of Florida panther (Puma concolor coryi) mortality and were a serious mortality factor for Key white-tailed deer (Odocoileus virginianus clavium) before mitigation measures were put in place (Forman and Alexander 1998). Collisions with wildlife also affect humans. In the United States every year WVCs involving deer (Odocoileus sp.) cause 150-200 human deaths, >29,000 human injuries, and monetary damages averaging $>\$ 6,600$ per collision (Huijser et al. 2009, Mastro et al. 2008, Stull et al. 2011). 
Various strategies have been implemented to reduce WVCs, usually by attempting to modify animal behavior near the road. The most successful strategy has been the installation of wildlife exclusion fencing combined with crossing infrastructure (Stull et al. 2011, Rytwinski et al. 2016). In some areas, wildlife fencing reduced WVCs involving large mammals by $80-100 \%$ (Huijser et al. 2015). However, despite well designed and maintained wildlife exclusion fencing, complete elimination of WVCs is impractical if animals can enter the highway corridor at the ends of the fence or via access roads within the fence (Clevenger et al. 2001). In these scenarios, the probability of a WVC in certain areas (often near fence ends and access roads) is increased because the animals are now trapped between the fence and the road. For example, in Canada, WVCs were associated with fence ends, and were actually higher than in non-fenced parts of the road (Clevenger et al. 2001). This same pattern was also found for wildlife in Montana (Huijser et al 2016).

Several strategies have been implemented to solve this problem, such as one-way gates (see Huijser et al. 2015) and earthen escape ramps (“jumpouts"). Jumpouts are sloped mounds of earth that angle up to near the height of the fence, then abruptly drop off, essentially becoming a continuation of the fence on the non-highway side (Figure 2.1). Jumpouts are designed to encourage animals to walk up the ramp and jump out to the safe side of the fence, while preventing them from traversing the ramp in the other direction. In Utah, Bissonette and Hammer (2000) compared mule deer (Odocoileus hemionus) use of one-way gates and jumpouts and found $1.5 \mathrm{~m}$ high jumpouts to be $8-11$ times more effective than one-way gates. In the time since the Bissonette and Hammer (2000) study, several studies have examined ungulate use of jumpout ramps and the 
associated reduction in WVCs. For example, bighorn sheep (Ovis canadensis) in Arizona jumped out in $96 \%$ of their detection events on the ramps (Gagnon et al. 2013), and in Colorado, installing jumpouts caused a significant reduction in the rate of WVCs involving mule deer (Siemers et al. 2015). However, important questions remain regarding wildlife use of jumpouts, even by closely-related species. Ideal jumpout height has not been standardized and may very well be species dependent (Huijser et al. 2015). Additionally, studies <2 years may not allow sufficient time to document how species to learn to use the jumpouts (Clevenger and Huijser 2011).

The objective of our study was to quantify wildlife use of jumpouts along a major highway, with mule deer (Odocoileus hemionis californicus) as our focal species. Considering how important mule deer are from a highway safety perspective, we decided to investigate their activity more deeply. A preliminary analysis of the first two years (2012-2014) of data by Perrine (2015) revealed that deer clearly used the jumpouts, but this only happened $6 \%$ of the time. For this study, we expected the jumpout rate (the proportion that jumpout when detected at the top of the ramp) to remain below $50 \%$, but to increase over time as the population became accustomed to the jumpout. Further, Perrine (2015) found that estimating the probability of jumping out was confounded by the same individuals returning day after day ("pseudoreplication"). If the same individuals are returning day after day, the observed proportion of events that result in jumping out would not be a reliable indicator of the probability of any given deer using the jumpout ramp, but the same individuals would instead be pseudoreplicates (Hurlbert 1984). To our knowledge, no previous research on jumpouts has attempted to account for pseudoreplication as we do here. 
We were also interested in how deer demographics relate to jumpout use. Perrine (2015) suspected that male and female deer were using the jumpouts differently but did not investigate further. We expected male deer to jump out more often than female deer, and juvenile deer to jump out less than adults because of the risk associated with jumping out. No previous research has addressed how sex and age relate to jumpout use for any species.

\section{METHODS}

\section{Study Site}

Our study site was a 4 km section of US Highway 101 in San Luis Obispo County, California (latitude 35.365, longitude -120.638), which is a major regional transportation corridor with traffic volume of up to 4,000 vehicles per hour (Snyder 2014). Just north of the city of San Luis Obispo, the highway crosses through the Santa Lucia Mountains, an area dominated by natural land cover and part of the Los Padres National Forest (Figure 2.2). The surrounding landscape is indicative of the California Woodland Chaparral Ecoregion, which is characterized by oak woodland and chaparral with annual and perennial grasslands, and relatively small amounts of riparian habitat (deVos et al. 2003). Here, the dominant species in oak woodland habitat are Coast live oak (Quercus agrifolia), Poison oak (Toxicodendron diversilobum), Toyon (Heteromeles arbutifolia), Ceanothus spp. (e.g., California lilac), and Artostaphylos (Manzanitas and Bearberries; Barbour et al. 2007). The dominant species in the Chaparral habitat are California Sage (Artemisia californica), Black Sage (Salvia mellifera), Coyote Bush (Baccharis pilularis), and Mountain Mahogany (Cercocarpus spp.; Barbour et al. 2007). The climate 
is "Mediterranean", with hot dry summers, mild wet winters, and substantial annual variation in precipitation (Sommer et al. 2007).

Recent habitat suitability modeling has identified this area as an important regional and local movement corridor for large mammals such as mountain lion (Puma concolor), mule deer and black bear (Ursus americanus; Thorne et al. 2006, Thorne and Huber 2011), and roadkill surveys have indicated that this area is a hotspot for roadkills of these taxa (Siepel et al. 2013). To minimize large-mammal roadkills and protect human safety, the California Department of Transportation (hereafter, CalTrans) constructed a $4 \mathrm{~km}$ wildlife exclusion fence, including $42 \mathrm{~m}$ high jumpout ramps, through the wildlife hotspot in April 2012 (Figure 2.2). For more details on the fencing project and its infrastructure, see Siepel et al. 2013 and Perrine 2015.

\section{Data collection}

Wildlife activity at each jumpout was monitored using Reconyx HC600 Hyperfire (Reconyx, Holmen, WI, USA) cameras with a motion activated trigger and infrared flash. Cameras were deployed continuously from July 2012 through August 2017. The cameras were aimed at the top of the jumpout, and set to take 3 photos per trigger event with "no delay" between triggers. We checked each camera monthly, which entailed swapping out data cards, replacing low batteries, and ensuring that the camera was aimed correctly and in good working order.

\section{Data analysis}

After reviewing the photographs, we recorded the number of detection events, which represented one or more individuals of the same species at a jumpout at a certain time. A single detection event could range from 3 photos (1 trigger) to hundreds of 
photos. To account for potential dependence between events we set a 15-minute buffer period before another detection of the same species at the same site was considered a different event. For each event at each jumpout, we recorded the date, time, species, number of individuals involved, number of juveniles and adults, and how many deer had antlers or not. We also assigned each event one of the following 4 outcomes: 1 . The animals approached from outside the wildlife exclusion fence and stayed outside; 2 . The animals approached from outside and went inside (i.e., they scaled the jumpout wall to enter the fenced highway corridor; 3 . The animals approached the ramp from inside the fence and stayed inside (i.e.,, they did not jump out, but rather returned back down the ramp toward the highway); 4. The animals approached the ramp from inside and went outside (i.e.,, they jumped out). Detection events with ambiguous outcomes were excluded from subsequent analyses. We counted animals of the same species traveling together as one detection event, because their activity was likely interdependent (Allen et al. 2013). We recorded all events consisting of large and medium sized mammals. We also detected birds, reptiles, rodents, rabbits, humans, and domestic cats and dogs but did not include them in subsequent analyses.

In order to quantify the amount of pseudoreplication we aimed to identify individual deer (or groups of deer). Differentiating adult males and females during the months that males bear antlers was straightforward, and we could differentiate males from each other by antler length and point count. Male mule deer bear antlers during most of the year, shedding them in January or early February and starting to re-grow them in late spring (California Department of Fish and Wildlife 2018). There is some variation in the timing of antler growth and shedding, which seems to be dependent on 
the nutritional quality of the individual's diet (Chapman and Feldhamer 1982). Our photographs were consistent with the literature; antlered deer were relatively rare during February through April, so we removed those months from the comparative analysis. We used ear shape (location of folds and notches) to differentiate females from each other. It was nearly impossible to differentiate individuals without antlers or ear notches (e.g., most juveniles), and sometimes fog obscured the image. In these cases, we identified those individuals as novel even though some of them were likely to be pseudoreplicates. We categorized an individual as a juvenile if it was spotted and/or a small antlerless deer clearly associated with a larger doe. Data compilation, analysis, and visualization were completed using Microsoft Excel 2016 and JMP 13 (SAS Institute Inc., Cary, NC, USA). Analysis consisted of comparisons between groups of deer; we did not conduct any statistical tests because we pooled our data across sites and a majority of the events were pseudoreplicates.

\section{RESULTS}

We surveyed for a total of 7,361 nights across all 4 sites. The cameras were fully operational for 7,132 (97\%) of these nights (Table 2.1). There were 1015 total detection events at the jumpouts, of which mule deer accounted for 895 (88\%) of them. We also detected black bear, bobcat (Lynx rufus), coyote (Canis latrans), gray fox (Urocyon cinereoargenteus), opossum (Didelphis virginiana), raccoon (Procyon lotor), red fox (Vulpes vulpes), striped skunk (Mephitis mephitis) (Table 2.2). With the exception of mule deer (895), grey fox (57) and raccoon (12), every other species was detected less than 10 times. Grey fox jumped out 9 of the 57 times (16\%), and reversed the jumpout 3 
(5\%) times. We never detected mountain lion, feral pig (Sus scrofa), or badger (Taxidea taxus) despite them being known to occur in our study area (Siepel et al. 2013, Perrine 2015). We detected bear at the top of the jumpout 4 times, which resulted in a successful jumpout 1 time.

Deer activity was relatively consistent across years with the exception of 2017 (Figure 2.3). On average, there were 14-20 deer events per month from 2012-2016 and 4 events per month in 2017. In 299 of the 895 (33\%) deer detection events, the deer were detected below the jumpout ramp on the outside of the wildlife exclusion fence, but they never jumped up onto the ramp and into the highway corridor. In the remaining 596 events, the deer were first detected on the ramp inside the wildlife exclusion fence. For 5 of these, the outcome was ambiguous, so these events were excluded from further analysis. Of the remaining 591 events, deer jumped out in 119 (20\%) of them. After identifying individuals from these 591 events, we found that at most 198 (34\%) of them were independent events. In other words, at least $66 \%$ of the events could confidently be identified as previously documented individuals (pseudoreplicates). Of the 198 unique individuals or groups, 157 were detected once, 24 were detected twice, and 10 were detected from 3 to 7 times. There were 4 individuals/groups that were detected 10-30 times, one group 89 times, and one group 153 times. The 6 groups that were detected $>10$ times accounted for 318 (54\%) of the 591 on-ramp detection events, and the last two groups accounted for 243 (41\%) of the 591 on-ramp detection events. Nearly all of the activity occurred at one site (Hwy 58S), which had 553 (94\%) of the 591 on-ramp events (Table 2.3). We did not detect the same individual or group at more than one site. 
In order to compare use between male and female deer, we removed detections from February-April, (when lack of antlers made identifying sex impossible) and events comprised only of juveniles. A total of 473 events remained (Table 2.4). Male deer were detected 64 times, of which they jumped out 14 times (22\%; Figure 2.4). In general, male deer were much less likely to return to the jumpout compared to females; of the 64 detections, 48 (75\%; Figure 2.4) were unique individuals. In other words, $16(25 \%)$ of the male detections were repeat visits by the same individual(s). Five individuals were detected twice, 2 individuals were detected 3 times, and 2 different individuals were detected 4 and 5 times, respectively.

Female deer were detected 408 times and jumped out 97 (24\%) of those times (Figure 2.4). Female deer were much more likely to return to the jumpout than males; 134 of the 408 (33\%) events were identified as different individuals, so $67 \%$ of the events were repeat visits by previously-documented females (Figure 2.4). A total of 113 individuals were only detected once, yet it is highly likely that some of these individuals were pseudoreplicates that could not be differentiated. The group that accounted for 153 detections we called ("Group A"), and the group that accounted for 89 detections we called (“Group B"). Group A consisted of 3 adult females, and Group B consisted of a doe and trailing yearling. Group B jumped out 64 (72\%) of those times, which inflated the overall proportion of successful jumpouts. Both of these groups were only detected at one site (Hwy58-S).

In order to assess acclimation to the jumpouts, we looked at the long term activity of Groups A and B. Group A was detected from April of 2013 until August 2017 (when the cameras were removed). They were detected 30 out of $48(63 \%)$ months in this 
period, and their activity was highest in the winter months (December-February). Within the 30 months Group A was detected, they were detected an average of 4.4 times per month (SE 1.79), with a maximum of 25 detections in a single month. Group A did not jump out for the first 107 times they were detected on the ramp then finally did so in April 2016, 36 months after their first visit. They then visited the ramp 12 times without jumping out, then jumped out again in November 2016. After that, they jumped out in 15 (47\%) of the remaining 32 times they were detected on the ramp. On average, events for this group lasted 15 minutes, and 34\% of events lasted 1-2 minutes. Nine events lasted longer than 60 minutes, and the longest event lasted 4 hours and 33 minutes.

Group B was detected 89 times from December 2015 through March 2017. They were detected in $8(50 \%)$ of the 16 months in this period, and their activity was concentrated in early 2016. Within the 8 months Group B was detected, they were detected an average of 11.1 times (SE 3.33) per month, with a maximum of 32 detections in one month (January 2016). During this month, Group B returned to the jumpout nearly every day, and sometimes multiple times per day. They did not jump out the first 2 times they were detected on the ramp (in December 2015), but then proceeded to jump out the next 3 events. These first 5 events contained only the doe, then its fawn appeared in the $6^{\text {th }}$ detection. The pair did not jump out the first time they were detected together at the jumpout, but then proceeded to jump out together for the following 7 events. Of the remaining 76 detections, they jumped out 52 times (68\%), but there was no clear pattern across time. Additionally, sometimes this group would loiter at the top of the ramp for an extended amount of time during a single detection event (Figure 2.5). On average, this group stayed on and near the top of the jumpout ramp for 13 minutes, and 63\% of events 
lasted 1 minute or less. Four events lasted more than 1 hour, and the longest was 7 hours and 11 minutes.

Four other groups of females and fawns were detected between 10 and 30 times each (Groups C-F, Table 2.5), totaling 75 events. These groups never jumped out. There were 4 other groups of deer that contained at least one buck (Groups G-I, Table 2.5), which accounted for a total of 15 events. Three of these groups consisted of a single buck and a single female, and 1 "group" was a solitary buck. In contrast to the 4 female groups, 2 of these "with buck" groups jumped out on their $3^{\text {rd }}$ visit to the jumpout (Table 2.5).

Juvenile deer were present in $142(24 \%)$ of the 591 events that began on the ramp, and they jumped out 47 times (33\%). However, $43(91 \%)$ of the 47 times a juvenile was detected jumping out can be attributed to Group B (consisting of a doe and one trailing juvenile).

\section{DISCUSSION}

Jumpouts are a promising advance in reducing WVCs, but remain relatively untested. To our knowledge, our study is the first to monitor long enough to document acclimation over multiple years (Clevenger and Huijser 2011), the first to account for pseudoreplication, and the first to explore how intraspecific differences may influence jumpout use.

Compared to deer, there were a handful of bear detections and no mountain lion detections. Mountain lion and bear were certainly less abundant than deer in our area, but we have detected them at other locations nearby (see Perrine 2015 for more details). We 
have evidence that bear and mountain were crossing electrified wildlife guards ("electromats") near 2 of the jumpouts, and on 2 occasions bear were subsequently detected at the jumpout (Perrine 2015). Deer usually travel parallel to roads before attempting to cross (Puglisi 1974), while bear and mountain lion may try to cross sooner, thus limiting their chances of encountering a jumpout. Likewise, deer may feel more comfortable closer to the highway than mountain lion and bear (Rytwinski unpublished), and further, we have evidence that carnivores may use some undercrossings more than deer (Perrine 2015), and therefore be less likely to cross the highway itself.

The height of the jumpout is probably the primary factor in determining the jump out rate, as well as how often the jumpout is reversed. The jumpout wall must be high enough to discourage wildlife from jumping over the wall and entering the highway corridor. Despite 4 reversals by mesocarnivores, we never detected a deer reversal in 299 detections below the ramp on the non-highway side of the fence. This number probably underestimates deer activity at the base of the ramp because our cameras were aimed at the top of the ramp rather than the base. To our knowledge, only 2 other studies have reported ungulates reversing jumpouts, and their jumpouts were different heights from ours. In Arizona, desert bighorn sheep reversed 1.83m jumpouts in 44 (3\%) of 1312 detections on the outside of the fence; the reversals stopped after horizontal bars were added at the appropriate height above the top of the wall (Gagnon et al. 2013). In Colorado, there were $27(0.9 \%)$ mule deer reversals out of 2,965 visits to their 11 jumpouts from 2012-2014 (Siemers et al. 2015). The jumpouts in Colorado varied in height between $1.4 \mathrm{~m}$ and $2 \mathrm{~m}$, and some had horizontal bars which raised their effective height from $1.8 \mathrm{~m}$ to $2 \mathrm{~m}$. The bars were installed about $0.5 \mathrm{~m}$ above the jumpout wall, and 
were intended to raise the effective height of the jumpout from perspective of the nonhighway side without hindering animals from jumping out (Jeremy Siemers pers. comm.). The Arizona Department of Transportation (2013) recommends a height of 1.7 $1.8 \mathrm{~m}$, and Huijser et al. (2015) suggest jumpouts $1.5 \mathrm{~m}-2.1 \mathrm{~m}$ high appear to function best for mule deer, elk, and bighorn sheep. The jumpouts in our study were $2 \mathrm{~m}$, which was clearly high enough to discourage use to enter the highway corridor, yet perhaps too high to encourage jumping out by a majority of individuals. Ideal height may very well be species dependent, as different species have different jumping and climbing capabilities.

In addition to its height, the texture (e.g., ease of purchase) of the jumpout wall is relevant for species that can climb (Clevenger and Huijser 2011). The walls of our jumpouts were made of plastic polymer planks buttressed by metal fence posts, which provided minimal purchase for climbing species. Additionally, when our jumpouts were first constructed they had a wooden plank that created a lip at the top of the jumpout wall to discourage animals from climbing or jumping in. However, this plank was removed in 2015 after we obtained photo sequences that suggested that the flexion of the board may have deterred deer from standing on it to jump out. We cannot conclusively determine whether removing the plank had any effect on the jumpout rate because it is confounded by pseudoreplication.

If the wildlife exclusion fence had worked perfectly, there would have been no deer detected on top of any of the jumpout ramps. We did not expect this, and indeed, deer did enter the highway corridor somehow and accessed all 4 jumpouts. Not accounting for pseudoreplication, deer jumped out about $20 \%$ of the time. This is a 
similar to a study in Canada that documented successful "escapes" by deer (19\%), elk (67\%), and coyote (25\%), however, there were only 33 total detections across these 3 species (Clevenger et al. 2002). Subsequent studies have reported higher rates of jumping out. For example, in Arizona, bighorn sheep jumped out using 1.83m jumpouts 95\% (322 of 337 events) of the time (Gagnon et al. 2013), and in Colorado, mule deer jumped out $51.5 \%(1333 / 2588)$ of the time using 1.3-2m jumpouts during a 2 year study (Siemers et al. 2015). The wide variation in jumpout height for the Siemers et al. (2015) study was due in part to the addition of horizontal bars which raised the effective height of the jumpout. Further, there appear to be differences between the 2 deer species in the U.S.: a study in Montana found that mule deer were 17 times more likely to jump out than whitetailed deer (Huijser et al 2013). However, these studies did not account for pseudoreplication, which could have potentially inflated the ratio of successful escapes in those studies.

Ideally, we would have liked to explore relationships between successful jumpout use and characteristics of the jumpouts. Unfortunately, this was impossible given our sample size of 4 jumpouts. A study in Colorado with 11 jumpouts was able to quantify some relationships, and suggested that the presence of a guide fence, shrubs closer to (but not in) the landing area, and proximity to the highway all positively affected jumpout success (Siemers et al. 2015). Location and spacing of jumpouts may be just as important as characteristics of the jumpouts themselves. The Arizona Department of Transportation (2013) recommended a jumpout every $0.8 \mathrm{~km}$ on both sides of the road, while others have recommended one every $0.4 \mathrm{~km}$ (Huijser et al. 2015). Our jumpouts were $\sim 3.2 \mathrm{~km}$ apart on one side of the highway and $\sim 1.6 \mathrm{~km}$ apart on the other side. There may be no universal 
ideal spacing between jumpouts, but placement may be most effective in areas where animals are most likely to enter the road corridor (i.e., near fence ends and access roads).

\section{Group dynamics}

If the same individuals return to the same jumpout multiple times, those events are not independent, but instead pseudoreplicates. We identified at least $386(66 \%)$ of the 584 deer detection events as individuals or groups that returned to the same jumpout more than once. In fact, just two groups of deer (totaling 5 individuals) accounted for $47 \%$ of the deer detections over 5 years. This phenomenon is not unique to this project: in Georgia, a single individual white-tailed deer accounted for $>50 \%$ of 1,400 highway crossings recorded in one year (Stickles et al. 2015).

Group A consisted of three female deer. This group was not always together; a single deer identified by a unique ear notch pattern was detected more often than the other two, but they were all detected together frequently enough to warrant grouping. In comparison, Group B (more details below), was detected less frequently yet over a period of time that was three times as long (51 vs. 16 months). Group A in particular appeared to "learn" to use the jumpout. They were detected at the jumpout 107 times in 3 years before jumping out for the first time. During the last 10 months of the study, they jumped out $15(47 \%)$ of 32 times suggesting that they had grown somewhat comfortable with this behavior.

Group B consisted of a doe and yearling pair that would return to the same jumpout day after day. Apparently, the jumpout became a part of their daily movement patterns. This pair foraged at the top of the jumpout, and even bedded down at times. In contrast to Group A, this pair jumped out more often and jumped out for the first time in 
the first few visits to the jumpout. It's possible they felt threatened during the first jump outs, then learned that they could safely jump out after that. A more likely explanation is that once the doe learned that jumping out was safe, her fawn simply followed suit. The raised ramp provided food, visibility in all directions, and the option to return down the ramp or jump out depending on where the deer might feel threatened.

We answered the question of whether deer used the jumpouts rather quickly; after the first week of monitoring we obtained photo sequences of a deer using one of the jumpouts to escape the highway corridor. Using Groups A and B, we were able to explore long term acclimation to the jumpout that these groups used. Interestingly, these two groups' long term patterns were quite different: Group A appeared to learn to use the jump out, while Group B starting jumping out relatively soon after their initial detection. Monitoring for 5 years gave us previously unknown insight into how resident deer use jumpouts over an extended time, since large mammals can take 5-6 years to acclimate to new highway infrastructure (Clevenger and Huijser 2011).

\section{Deer behavior}

Deer in our area are most likely non-migratory, staying in the same general vicinity while taking advantage of different microclimates within their home range (Taber and Dasmann 1958). Further, deer home ranges tend to be relatively small; studies on other subspecies of Mule deer have found that they range from $0.5-3 \mathrm{~km}^{2}$, with males having larger home ranges than females (Harestad and Bunnel 1979). In general mule deer are habitual animals, which includes their daily activity patterns (Chapman and Feldhamer 1982). This probably explains why Group B would return to the jumpout day after day: they incorporated it into their daily activity pattern. Further, there can be 
significant variation in behavior between individual deer (Chapman and Feldhamer 1982), which is potentially why some groups would return to the jumpout over and over and others were only detected once.

Except for during the mating season, male and female deer are generally segregated from each other (Main and Coblentz 1990). The leading hypothesis is that this is primarily due to sex-specific strategies to maximize fitness. In Oregon, female mule deer tended to use areas with low coyote activity, security benefits, palatable browse resources, and proximity to water, whereas males used areas that optimized foraging opportunities (more biomass and species richness of forbes; Main and Coblentz 1996). The factors that are associated with female space use are all likely to maximize offspring survival. Roads can have a stronger negative effect on predators than their prey species, which may be a factor in why small mammal population density can be positively associated with roads (Rytwinski unpublished), and possibly why female deer (and their fawns) were detected more frequently at the jumpouts in our study.

\section{Management Implications}

Jumpouts have been shown to be effective escape opportunities for large mammals. Based on our data in the context of previous research, we recommend a jumpout height lower than $2 \mathrm{~m}$, but probably not lower than $1.75 \mathrm{~m}$ for mule deer (similar to Huijser et al. 2015), yet the ideal height might very well be different for other species. Jumpouts slightly lower than $2 \mathrm{~m}$ may increase jumpout rate while still discouraging animals from jumping in. The addition of horizontal bars seems to decrease how many animals reverse the jumpout, while still allowing them to jump out safely, (Gagnon et al. 2013) but more research is needed into what factors contribute to successful jump outs. 
Jumpout use by one group of deer suggests that they may acclimate to the jumpouts over time. A necessary step is to radio collar individual animals to quantify habitat selection and determine how animals are using the landscape near and around the highway so that jumpout placement could be optimized. This true for deer, as well as mountain lion and bear, especially given the amount of individual variation in behavior in deer we have described above. 
Table 2.1: Camera performance across all 4 sites. "Day active only" indicates that the camera was not functional at night due to flash failure.

$\begin{array}{lcccc}\text { Site } & \text { Total Survey Nights } & \text { Active } & \text { Not active } & \text { Day active only } \\ \text { Hwy58-N } & 1840 & 1840 & 0 & 0 \\ \text { Hwy58-S } & 1840 & 1698 & 25 & 117 \\ \text { Wat-Dist } & 1840 & 1779 & 61 & 0 \\ \text { TjCk-N } & 1841 & 1815 & 26 & 0 \\ \text { Total } & \mathbf{7 3 6 1} & \mathbf{7 1 3 2} & \mathbf{1 1 2} & \mathbf{1 1 7}\end{array}$


Table 2.2: The number (\%) of detection events per species by site. These numbers are irrespective of group size.

$\begin{array}{lccccc}\text { Species } & \text { TjCk-N } & \text { Hwy58-N } & \text { Hwy58-S } & \text { Wat-Dist } & \text { Total } \\ \text { Bobcat } & 1(16 \%) & 0 & 4(67 \%) & 1(16 \%) & \mathbf{6} \\ \text { Bear } & 2(40 \%) & 1(20 \%) & 0 & 2(40 \%) & \mathbf{5} \\ \text { Coyote } & 1(16 \%) & 1(16 \%) & 4(67 \%) & 0 & \mathbf{6} \\ \text { Mule deer } & 102(11 \%) & 157(18 \%) & 573(64 \%) & 83(9 \%) & \mathbf{8 8 7} \\ \text { Grey fox } & 38(67 \%) & 0 & 15(26 \%) & 4(7 \%) & \mathbf{5 7} \\ \text { House cat } & 3(68 \%) & 1(16 \%) & 0 & 1(16 \%) & \mathbf{5} \\ \text { Opossum } & 2(29 \%) & 0 & 2(29 \%) & 3(43 \%) & \mathbf{7} \\ \text { Raccoon } & 7(58 \%) & 1(8 \%) & 1(8 \%) & 3(25 \%) & \mathbf{1 2} \\ \text { Red fox } & 2(100 \%) & 0 & 0 & 0 & \mathbf{2} \\ \text { Skunk } & 0 & 0 & 2(100 \%) & 0 & \mathbf{2} \\ \text { Turkey } & 0 & 3(38 \%) & 5(62 \%) & 0 & \mathbf{8} \\ \text { ? - Unidentifiable } & 0 & 14(93 \%) & 1(7 \%) & 0 & \mathbf{1 5} \\ \text { Total } & \mathbf{1 5 8} & \mathbf{1 7 8} & \mathbf{6 0 7} & \mathbf{9 7} & \mathbf{1 0 0 7}\end{array}$


Table 2.3: Number (\%) of deer detection events by site. 4 different outcomes relative to the wildlife exclusion fence: II means approached from inside and stayed inside (did not jump out), IO means approached from inside and went outside (jumped out), OO means approached the jumpout from outside and stayed outside, I? means the event started on the inside (on top of the jumpout ramp) but the outcome was ambiguous, and OI means approached the jumpout from outside and jumped in.

\begin{tabular}{|c|c|c|c|c|c|c|}
\hline & Number of & \multicolumn{5}{|c|}{ Outcome } \\
\hline Site & Events & II & IO & 00 & I? & Ol \\
\hline Hwy 58-N & 157 & $33(21 \%)$ & $6(4 \%)$ & $118(75 \%)$ & 0 & 0 \\
\hline Hwy 58-S & 553 & $410(74 \%)$ & $109(20 \%)$ & $29(5 \%)$ & $5(1 \%)$ & 0 \\
\hline Wat-Dist & 83 & $6(7 \%)$ & $2(2 \%)$ & $75(90 \%)$ & 0 & 0 \\
\hline TjCk-N & 102 & $23(23 \%)$ & $2(2 \%)$ & $77(75 \%)$ & 0 & 0 \\
\hline Total & 895 & $472(53 \%)$ & $119(13 \%)$ & $299(33 \%)$ & $5(1 \%)$ & \\
\hline
\end{tabular}


Table 2.4: Outcomes of events that began at the top of the jumpout ramp for male and female deer. II means approached from inside and stayed inside (did not jump out), and IO means approached from inside and went outside (jumped out). Detections during the months of February, March, and April were removed.

\begin{tabular}{l|c|cc|cc} 
& \multicolumn{2}{|c}{ Female } & \multicolumn{2}{c}{ Male } \\
Site & Total & II & IO & II & IO \\
Hwy58-N & 36 & $17(47 \%)$ & $1(3 \%)$ & $14(39 \%)$ & $4(11 \%)$ \\
Hwy58-S & 447 & $312(70 \%)$ & $101(23 \%)$ & $28(6 \%)$ & $6(13 \%)$ \\
Wat-Dist & 8 & $1(13 \%)$ & 0 & $5(63 \%)$ & $2(24 \%)$ \\
TjCk-N & 19 & $14(74 \%)$ & 0 & $3(16 \%)$ & $2(11 \%)$
\end{tabular}


Table 2.5: Initial outcomes and jumpout ratios of 10 groups of deer detected multiple times. Groups A-F are composed of females and juveniles that were detected at least 10 times, groups G-J have a male deer in the group and were detected multiple times. IO indicates events where the group successfully jumped out.

\begin{tabular}{|c|c|c|c|c|c|c|}
\hline Group & Detections & IO & IO\% & $\begin{array}{c}\text { First } \\
\text { Event }\end{array}$ & $\begin{array}{c}\text { Events } \\
\text { until IO }\end{array}$ & Composition \\
\hline A & 153 & 17 & 11 & II & 107 & 3 adult females \\
\hline $\mathrm{B}$ & 89 & 64 & 72 & II & 2 & Doe and trailing yearling \\
\hline $\mathrm{C}$ & 28 & 0 & 0 & II & Never & 2 adult females \\
\hline $\mathrm{D}$ & 24 & 0 & 0 & II & Never & 2 adult females and 1 fawn \\
\hline $\mathrm{E}$ & 12 & 0 & 0 & II & Never & 3 adult females \\
\hline $\mathrm{F}$ & 11 & 0 & 0 & II & Never & 2 spotted fawns \\
\hline $\mathrm{G}$ & 5 & 0 & 0 & II & Never & Buck and female \\
\hline $\mathrm{H}$ & 4 & 1 & 25 & II & 2 & Buck and female \\
\hline $\mathrm{I}$ & 3 & 0 & 0 & II & Never & Buck and female \\
\hline $\mathrm{J}$ & 3 & 1 & 33 & II & 2 & Buck \\
\hline
\end{tabular}




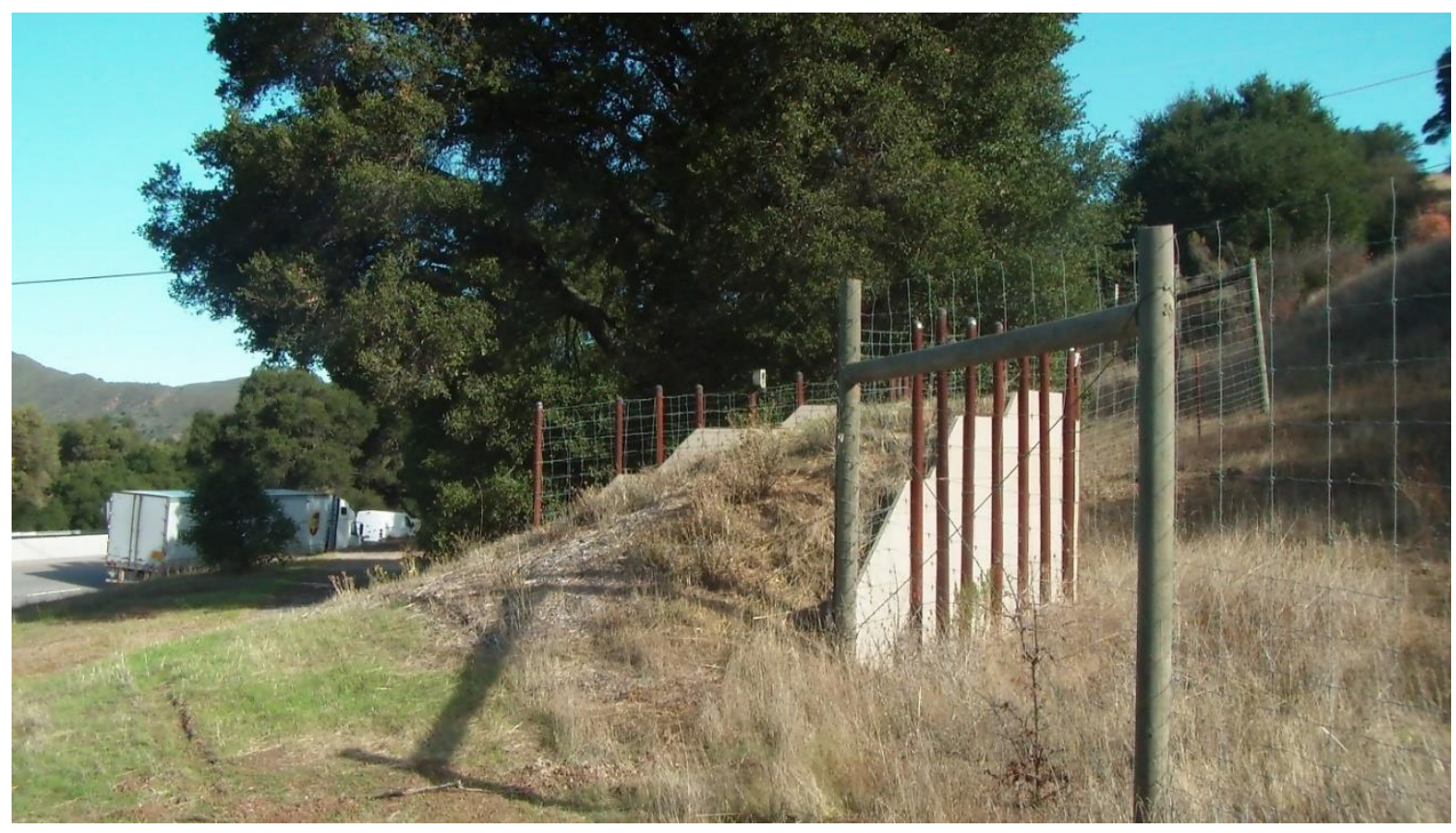

Figure 2.1: Jumpout ramp along Highway 101 in San Luis Obispo County, California (TjCk-N site). 


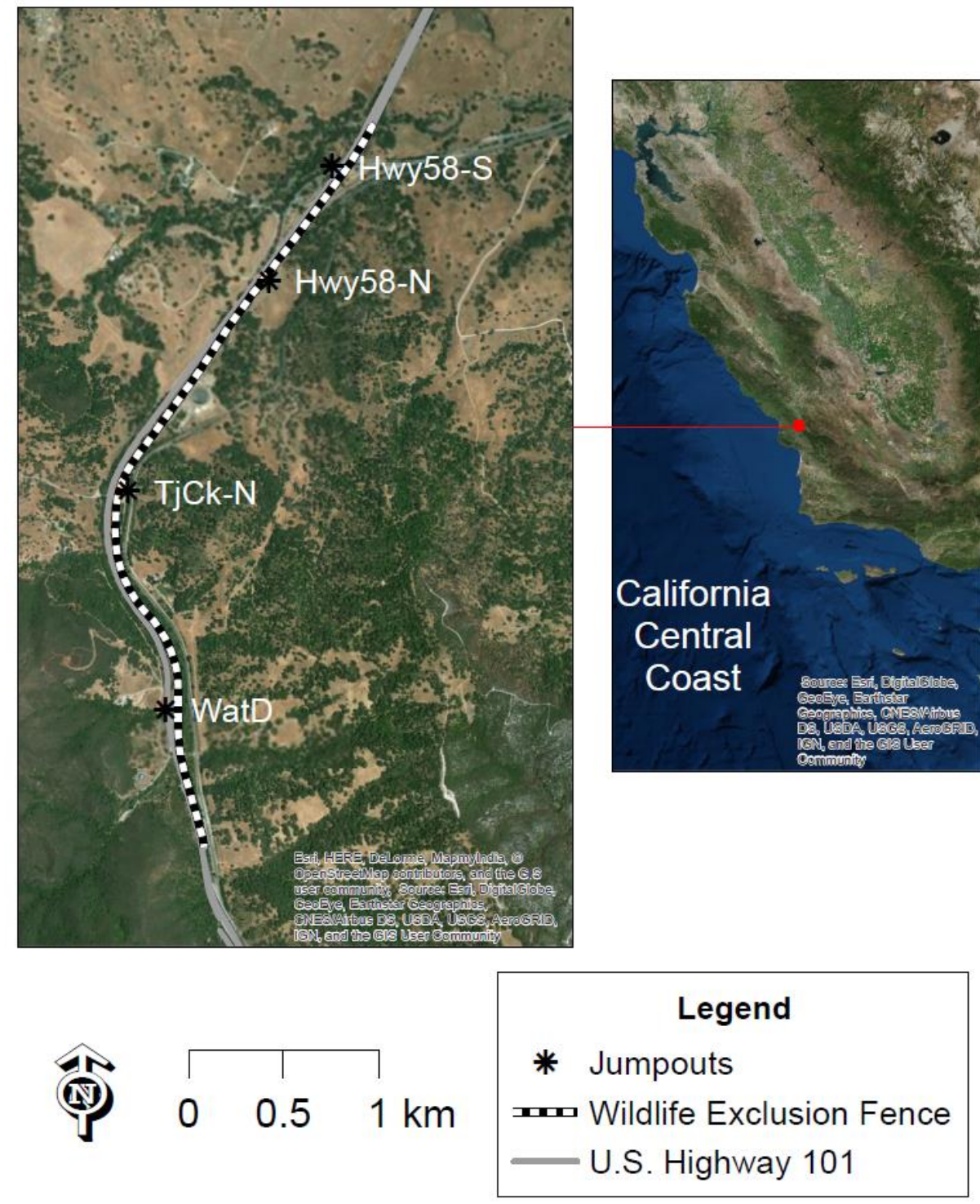

Figure 2.2: Four jumpouts along Highway 101 between San Luis Obispo and Atascadero, California. The wildlife exclusion fence is $4 \mathrm{~km}$ long. 


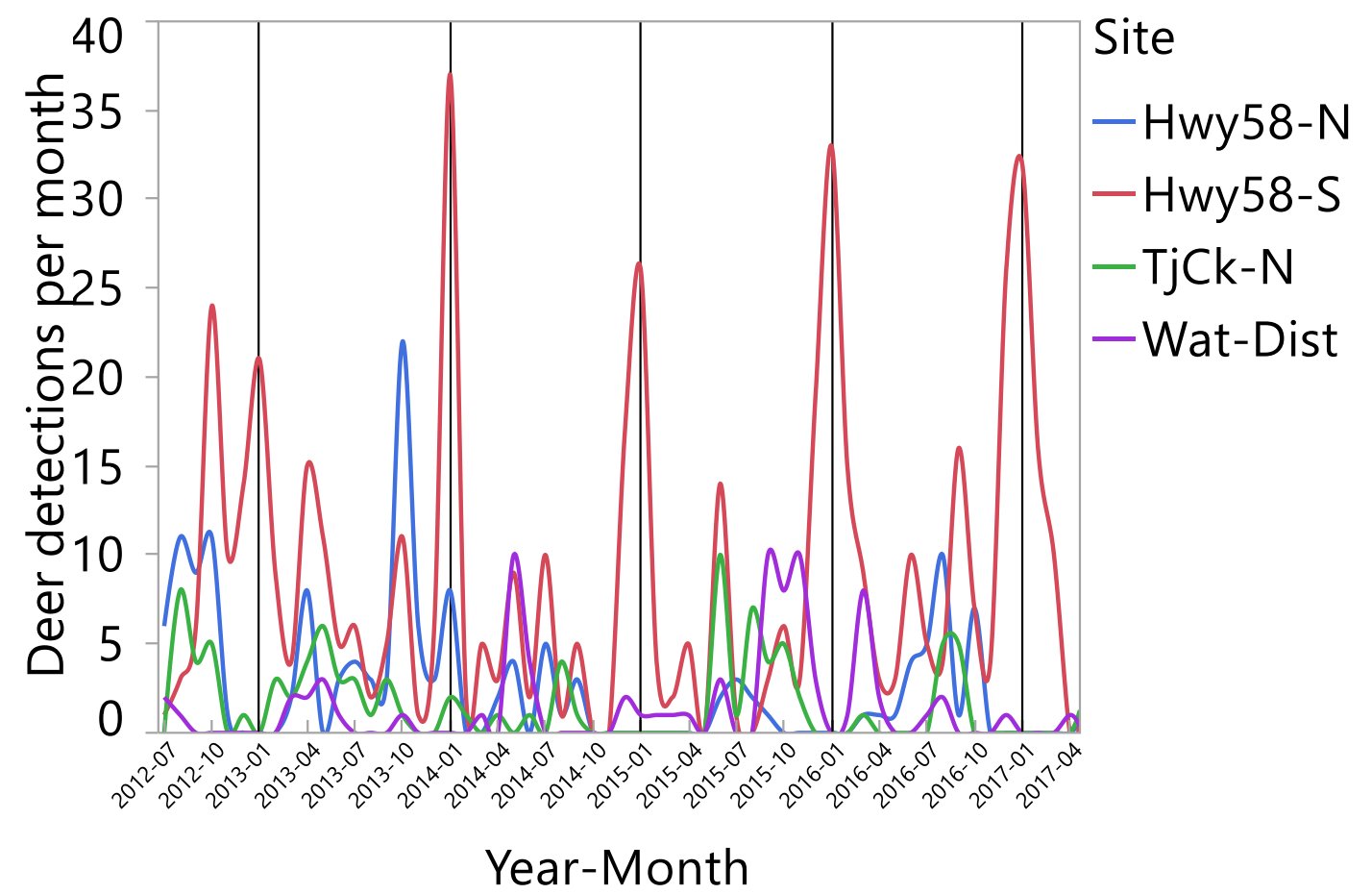

Figure 2.3: Deer activity at all 4 jumpouts irrespective of group size. 


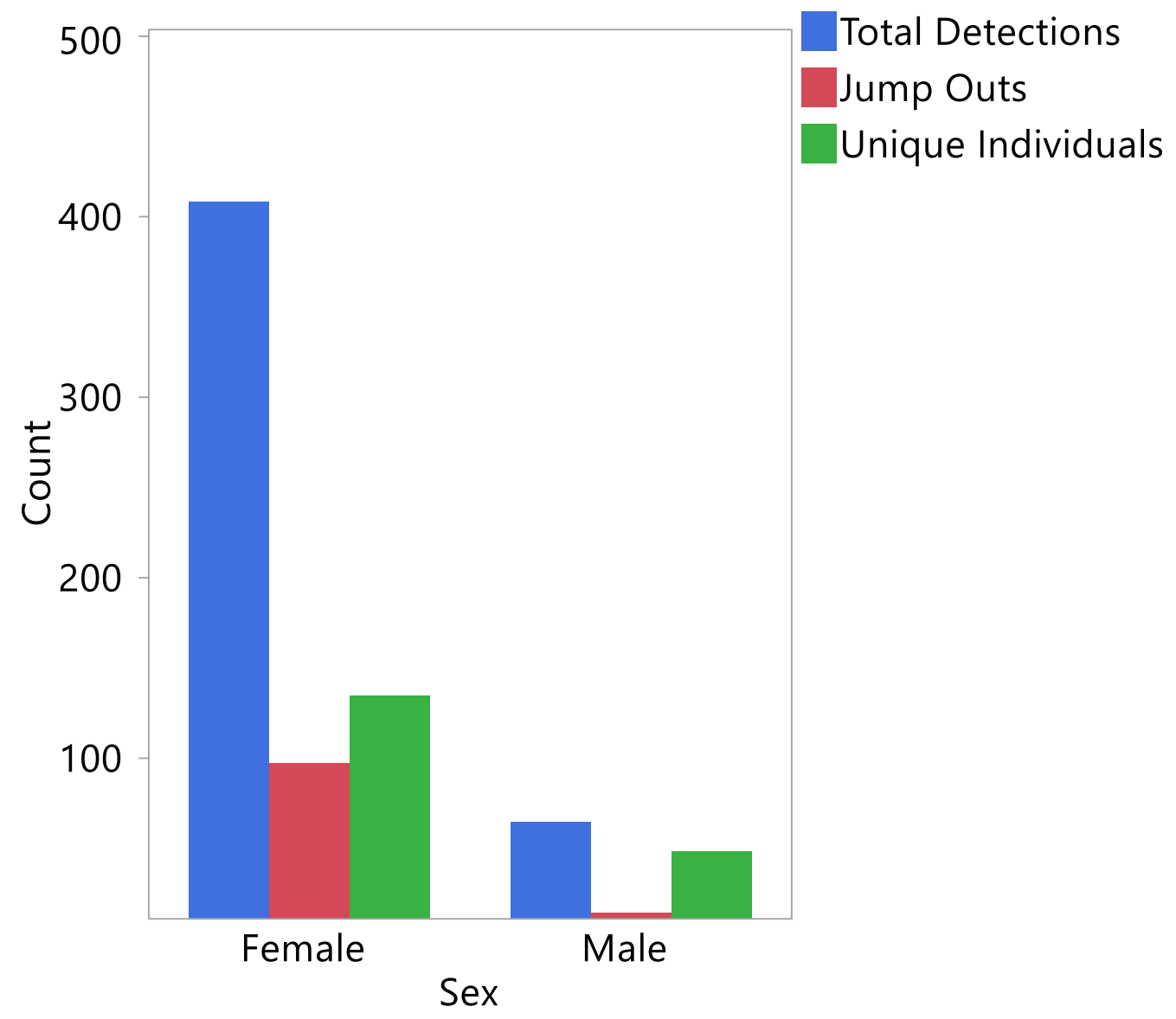

Figure 2.4: Comparison of male and female deer with the months of February-April removed. Total detections only includes events that started at the top of the ramp. Red bars indicate how many groups/individuals jumped out, and green bars indicate how many detections were unique groups/individuals. 


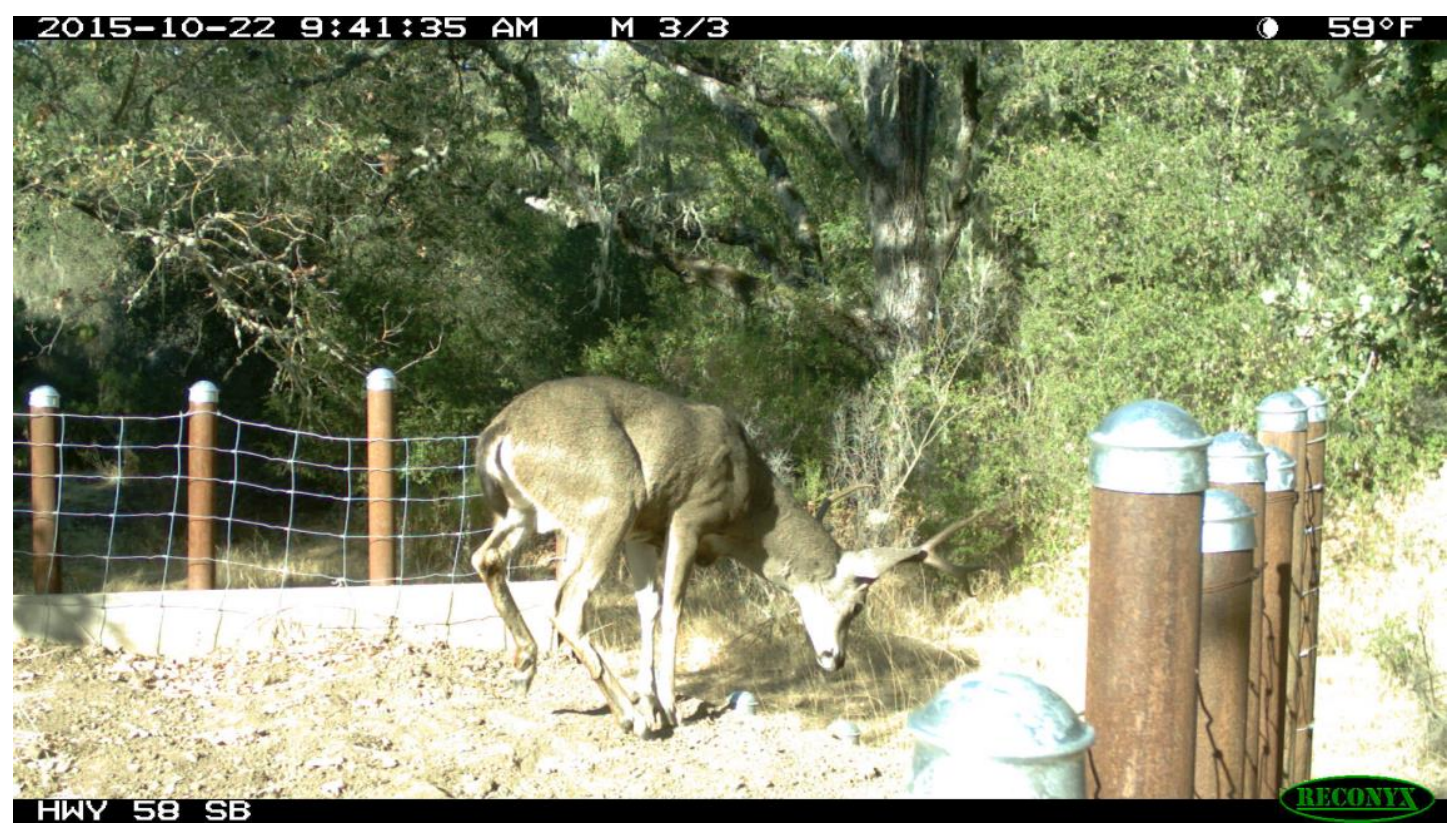

Figure 2.5: Male deer about to jump out at the Hwy58-S site. 


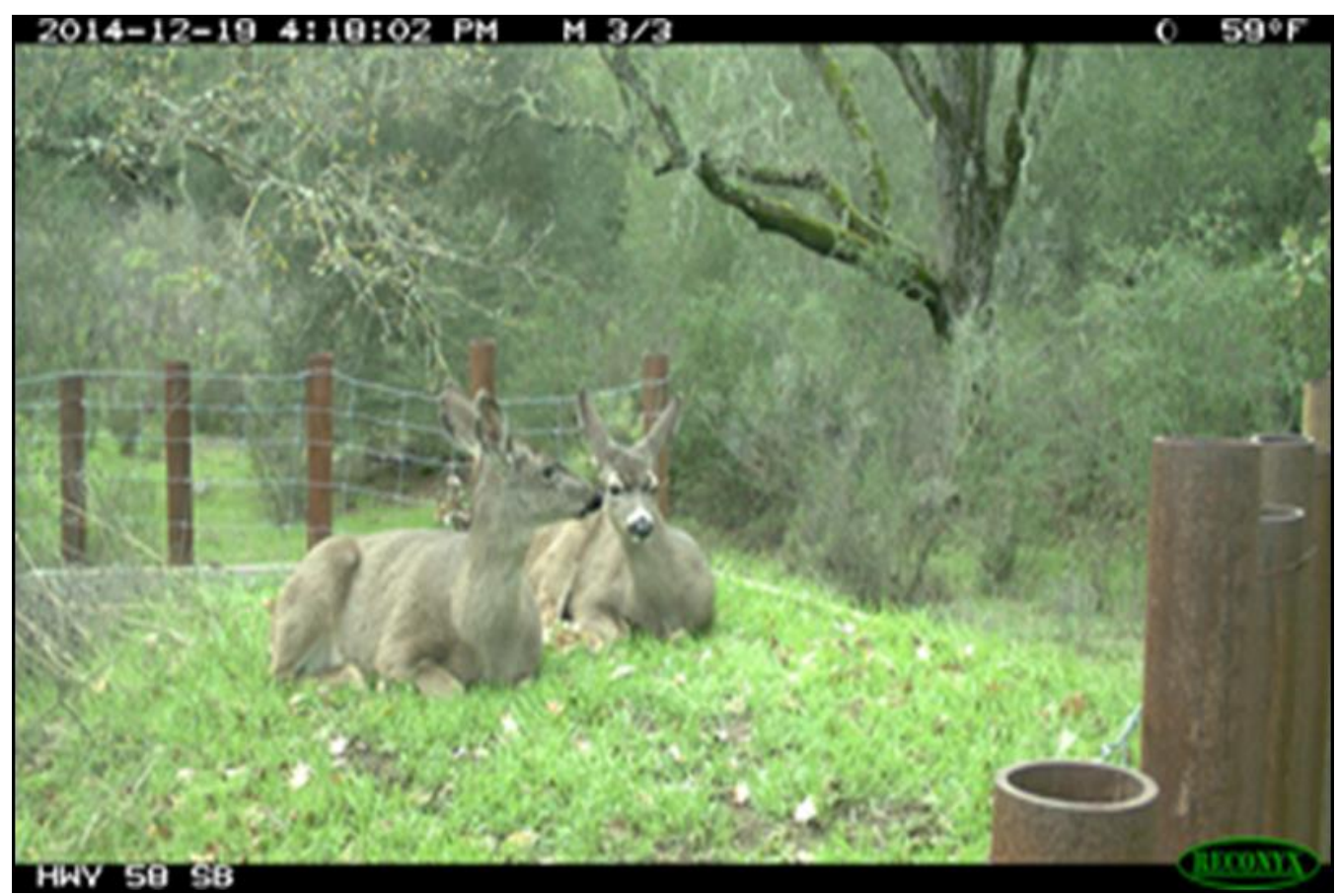

Figure 2.6: A doe and yearling fawn pair (Group B) bedded down the Hwy58-S jumpout. 


\section{CHAPTER 3}

\section{WILDLIFE USE OF UNDERCROSSINGS ALONG A HIGHWAY WITH WILDLIFE EXCLUSION FENCING}

\section{INTRODUCTION}

Roads have significant ecological impacts, including direct and indirect effects upon wildlife populations and habitat structure (Forman and Alexander 1998). Wildlifevehicle collisions (hereafter WVCs) and the associated injuries and deaths to both wild animals and humans are the most apparent effects. It has been estimated that 1,000,000 vertebrates are killed on United States roads every day (Forman and Alexander 1998). The majority of these deaths are small, r-selected taxa like rodents and songbirds, which can reproduce faster than the rate they are killed by vehicles. However, for species that are less abundant (often large bodied and k-selected taxa), WVCs can be a significant population-level mortality factor. For example, 50\% of Florida panther (Puma concolor coryi) mortality, and a significant proportion of Key white-tailed deer (Odocoileus virginianus clavium) mortality was attributed to WVCs before safe crossing opportunities were constructed (Forman and Alexander 1998). WVCs involving large-bodied mammals such as deer (Odocoileus sp.) also affect human safety; every year in the United States deer-vehicle collisions cause >29,000 injuries (about 80 per day), 150-200 human deaths, and damages averaging $>\$ 6,600$ per collision (Mastro et al. 2008, Huijser et al. 2009, Stull et al. 2011).

In addition to direct mortality, roads can be significant barriers (Poessel et al. 2014) or filters (Clevenger and Waltho 2005) to the movement of wildlife. Forman (2000) estimated that $15-20 \%$ of U.S. land is ecologically affected by roads. Animals 
may not only hesitate to cross roads when encountered, but actively avoid them as well. Further, large mammals (especially carnivores) are vulnerable to habitat fragmentation because of their relatively large home ranges, lower population densities, and conflicts with humans (Crooks 2002). For example, in the Southwest U.S., mountain lion (Puma concolor) home ranges tended to be in areas with relatively lower densities of improved dirt and paved roads (Van Dyke et al. 1986). Similarly, in the Netherlands, high road density was explicitly linked to European badger (Meles meles) population declines, which was attributed to avoidance of disturbed habitat as well as vehicle mortality (Van der Zee et al. 1992).

Various mitigation measures have been used to modify animal behavior to reduce WVCs. Wildlife exclusion fencing has been found to be the most effective (non-lethal control) method for reducing collisions with deer (Clevenger and Huijser 2011). Despite reducing WVCs, wildlife fencing may further decrease a road's permeability for wildlife; therefore, it is suggested that fencing be designed to funnel animals towards crossing structures (Huijser at al. 2015). In some areas, well designed, implemented, and maintained wildlife exclusion fencing combined with wildlife crossings has resulted in an 80-100\% reduction in WVCs involving large mammals (Huijser et al. 2015).

Wildlife overcrossings and undercrossings have become the standard methods to increase road permeability. When compared to undercrossings, overcrossings seem to be used by a broader suite of species, although they are less common probably due to being more expensive to build (Clevenger and Waltho 1999, Van Wieren and Worm 2001). We categorize undercrossings into two categories: culverts and underpasses. Culverts are usually originally designed to carry water under roads, although they can be retrofitted or 
even built for the purpose of wildlife use. They can vary in size and composition from $0.3 \mathrm{~m}$ corrugated pipes to $4 \mathrm{mx} 4 \mathrm{~m}$ concrete box culverts. In contrast, underpasses are often taller, and much wider than culverts, providing much more open passage for wildlife. Further, underpasses are often built over natural substrate (as opposed to culverts which are often concrete or metal), which probably further facilitates wildlife use. As with the overcrossings, underpasses tend to accommodate a wider suite of species than culverts (Glista et al. 2009).

Our objective was to determine which factors are related to use of undercrossings by mule deer (Odocoileus hemonius californicus), black bear (Ursus americanus), mountain lion (Puma concolor), and bobcat (Lynx rufus). We chose deer as a focal species because a combination of their large size and abundance make them a significant safety concern for drivers. Mountain lion and bear are also a concern from a human safety standpoint, and regional connectivity is important for these wide-ranging species. Bobcats were a focal species because they can be an ecological indicator species for habitat fragmentation in California (Jennings 2013) by providing insight into connectivity on a sub-regional scale, and are representative of the mesocarnivore guild, which plays important ecological roles such as mediating trophic cascades (Roemer et al. 2009).

Many studies have documented wildlife use of undercrossings, but far fewer have attempted to correlate use with features of the undercrossings. Several studies have found that deer use larger and more open undercrossings (Mastro et al. 2008, Clevenger and Waltho 2005), and we expected to find these same patterns in our study area (see below). However, despite decades of research, it is still unclear which factors are associated with use by carnivores in particular. Some studies have found that large carnivores used 
smaller and longer undercrossings more than larger and shorter ones(e.g., Clevenger and Waltho 2005), but the associations were not as consistent as for deer. We expected mountain lion and bear to use smaller culverts more than larger ones, and surrounding habitat to have an effect on use. We expected bobcats to use smaller culverts more than larger culverts.

Most wildlife crossing monitoring projects may not be long enough to account for yearly variation and wildlife acclimation. The average monitoring duration of wildlife crossing projects is 17 months, while some species can take 5-6 to adapt to new infrastructure in their enviroment (Clevenger and Huijser 2011). We monitored most of our undercrossings for more than 4 years, and all but one for 2 years or more, which allowed us to account for yearly variation as well as long term acclimation to wildlife exclusion fencing.

\section{METHODS}

Study site

Our study was along a $19.3 \mathrm{~km}$ section of U.S. Highway 101 in San Luis Obispo County, California (latitude 35.365, longitude -120.638), between the cities of San Luis Obispo and Atascadero (Figure 3.1). In this region, Highway 101 is a major regional transportation corridor, with traffic volume of to 4,000 vehicles per hour (Snyder 2014). Just north of San Luis Obispo, the highway passes through the Santa Lucia mountains, which is part of a relatively narrow band of the Los Padres National Forest. The surrounding landscape is representative of the California Woodland Chaparral Ecoregion, which is characterized by oak woodland and chaparral communities, interspersed with 
annual and perennial grasslands, and some riparian habitat (deVos et al. 2003). Here, the oak woodland habitat is composed of Coast live oak (Quercus agrifolia), Poison oak (Toxicodendron diversilobum), Toyon (Heteromeles arbutifolia), Ceanothus spp. (e.g., California lilac), and Artostaphylos (Manzanitas and Bearberries; Barbour et al. 2007). The dominant species in the Chaparral habitat are California Sage (Artemisia californica), Black Sage (Salvia mellifera), Coyote Bush (Baccharis pilularis), and Mountain Mahogany (Cercocarpus spp.; Barbour et al. 2007). The region's climate is "Mediterranean", with hot dry summers, mild wet winters, and considerable annual variation in precipitation (Sommer 2007).

Computer modeling has identified this area as an important regional and local movement corridor for mountain lion, mule deer and black bear (Thorne et al. 2006, Thorne and Huber 2011), and field surveys have indicated that this area is a hotspot for roadkills of these taxa (Siepel et al. 2013, Shilling and Waetjen 2015). In particular, the roadkills were concentrated in a $4 \mathrm{~km}$ section of the highway where the surrounding habitat was relatively forested, and the computer models indicated higher levels of landscape connectivity for our focal species. To minimize large-mammal roadkills and protect human safety in this area, the California Department of Transportation (hereafter CalTrans) constructed a $4 \mathrm{~km}$ wildlife exclusion fence along the roadkill hotspot that was completed in April 2012 (Siepel et al. 2013; Figure 3.1).

\section{Data collection}

There were dozens of undercrossings along Highway 101 within and adjacent to the wildlife exclusion fence zone. Since our focal species were medium to large sized mammals we chose to document activity in only those with a width and height $\geq 1.2 \mathrm{~m}$ (4 
$\mathrm{ft})$ that were not clogged by debris. These criteria were met by 11 undercrossings ( 9 culverts and 2 underpasses) between San Luis Obispo and Atascadero. Of these, 4 of the culverts were inside the wildlife exclusion fence zone, 5 were outside, and the 2 underpasses were at the ends of the fenced zone.

Wildlife activity at each undercrossing was documented using Reconyx HC600 Hyperfire (Reconyx, Holmen, WI, USA) or Bushnell TrophyCam HD (Bushnell Outdoor Products, Overland Park, KS, USA) wildlife cameras with a motion activated trigger and infrared flash. We programmed each Camera to take 1-5 photos per trigger depending on the site. Data collection began in Fall 2012; 5 sites were monitored continuously until Fall 2017, and the other 6 were monitored for less time due to theft or risk of theft (Table 3.1). In general, one camera was mounted near the center of each culvert to document animals passing through the culvert, although this did not allow us to quantify how many animals approached the culvert and decided not to enter. However, at one site (Woods) the camera was mounted at one end facing the nearest entrance. Underpasses, being larger and wider, required multiple cameras to document wildlife use: 2 cameras at the railroad undercrossing (RR) site, and 3 cameras at the Santa Margarita Creek (SM) site. We checked the cameras every 4-6 weeks, which entailed swapping out data cards, replacing low batteries, and ensuring the camera was properly aligned and in good working order.

\section{Data Analysis}

After reviewing the photographs, we recorded the number of detection events, which represented one or more individuals at an undercrossing in a certain time frame. A single detection event could range from 1 photo to hundreds of photos. For each animal 
detection event at a site, we documented the date, start time and end time, species, number of individuals, and age class (adult or juvenile). For deer we also noted whether each individual had visible antlers or not. We counted animals of the same species traveling together as one detection event, because their activity was likely interdependent (Allen et al. 2013). To account for potential dependence between events we set a 15minute buffer period before a detection of the same species at the same site was considered a different event. We recorded each camera's performance by month and excluded months when the camera was active for $<10$ nights. We excluded photos from periods when the camera was inactive or otherwise malfunctioning (i.e., diurnal photos when the camera failed to flash at night). Reasons the camera was inactive included battery failure, full data cards, theft, and being knocked off aim.

Our dependent variable was the count of detections of a particular focal species per site per month. We chose 9 predictor variables: YEAR, SEASON, LANDSCAPE RESISTANCE, LENGTH, OPENNESS, DISTANCE TO COVER, SUBSTRATE, whether the undercrossing was in the wildlife exclusion FENCE zone, and HUMAN ACTIVITY. We used YEAR and SEASON in every model in order to account for temporal variation among and within years. We collected data in 6 different years: 20122017. SEASON had four categories: Winter (December-February), Spring (March-May), Summer (June-August), and Fall (September-November).

We used LANDSCAPE RESISTANCE in every deer, bear, and mountain lion model to account for the likelihood of deer, bear, and mountain lion being near the culvert entrances in the first place. Habitat suitability can sometimes be the strongest predictor of a particular species use of undercrossings (Yanes et al. 1995, Clevenger and 
Waltho 2000). No matter the species, if the undercrossing is in poor habitat, it is probably less likely to be used, and vice versa. In our case, LANDSCAPE RESISTANCE was modeled based on vegetative community, road density, and topography (Thorne and Huber 2011). We expected a higher value of LANDSCAPE RESISTANCE to indicate lower activity of a given focal species in that area. We followed the same assumption as Clevenger and Waltho (2000); namely, that each individual is aware of every undercrossing and can choose based on attributes alone. We used ArcMAP 10 (ESRI, Redlands, CA, USA) to create a 500m (same distance as Grilo et al. 2008) habitat buffer zone around each culvert center. We then split each circle in half using the "split polygons" tool with a Highway 101 layer (CalTrans California Highways) buffered by 20 meters to account for the right of way. We received landscape resistance surfaces for mountain lion, deer, and bear from Thorne and Huber (2011), and used the "Zonal Statistics" tool to find the average resistance value within each buffer zone (Table 3.2b). We chose the higher of the 2 resistance values for each undercrossing to be conservative, assuming that the higher value would be the most biologically relevant. Two culverts (58N and 58S) were in series with a $20 \mathrm{~m}$ uncovered drainage between them, so for these sites, we used the polygon on the east side of the highway for the culvert under the northbound lanes, and the polygon on the west side of the highway for the culvert closer to the southbound lanes. A resistance surface was not made by Thorne and Huber (2011) for bobcats because they are not a species of concern from a highway safety standpoint and landscape-level connectivity is not as important for bobcats as it is for our other focal species (Crooks 2002, Jennings and Lewison 2013). 
Undercrossing dimensionality has been shown to be an important predictor of wildlife activity (Clevenger and Waltho 1999, Mastro et al. 2008). We quantified undercrossing dimensionality by measuring the length, width, and height of each undercrossing (Table 3.2a). At two culverts the height was slightly different at each entrance so we averaged the two values. For the two underpasses we used Google Earth Pro (Google Inc. Mountain View, CA USA) to measure length and width, and used a tape measure to measure the height. Even though the highway was divided above each underpass we included the section between the northbound and southbound lanes in the length measurement. We used these values to calculate "openness" (Reed and Ward 1985), an index combining height, width, and length into a single value:

$$
\text { Openness }=(\text { height } \times \text { width }) \div \text { length }
$$

We also measured the shortest distance to cover from each culvert entrance, and averaged those two values for each site (Table 3.2a). We defined cover as any vegetation that was at least $1 \mathrm{~m}$ high and was dense enough to reasonably shelter a medium sized animal (like a bobcat). At 1 culvert (N 10.0), there was no cover within 100m of either entrance, and both underpasses were too wide to have an "entrance"; for these cases, we set the DISTANCE TO COVER to twice the longest distance to cover measured at any other site. For SUBSTRATE, we recorded the predominant substrate type in each undercrossing, as either concrete or natural sediment (Table 3.2b). Location relative to the wildlife exclusion fence refers to whether or not the undercrossing was located between the two ends of the wildlife exclusion fence (Table 3.2b). Human activity was quantified in nearly the same way as our focal species (Table 3.2b). Because it was much easier to differentiate humans from each other, we used a 6-hour buffer before identifying 
the same individual as a new event. We did not include members of our field team checking the cameras because this was consistent across all sites. We also recorded whether the culvert's exit could be seen from its entrance, but decided to remove it from the analysis because only one culvert was not see through.

We built zero-inflated Poisson regression models (Lambert 1994) to determine which factors were associated with undercrossing use by our focal species. YEAR, SEASON, and LANDSCAPE RESISTANCE were included in all deer, bear, and mountain lion models. An example model for deer would be YEAR, SEASON, LANDSCAPE RESISTANCE, LENGTH with underpass length being the variable of interest in this case. YEAR and SEASON were included in all bobcat models, so an example model would be YEAR, SEASON, LENGTH with length as the variable of interest. We considered standardizing each month using active nights to control for variation in survey effort, but this variance was so minimal ( $75 \%$ of months had 30 survey days, $90 \%$ of months had 28 survey days), that we decided this was not necessary. We fit zero-inflated Poisson regressions on the count of each of our focal species with the following factors as predictors: LANDSCAPE RESISTANCE, LENGTH, OPENNESS, AVERAGE DISTANCE TO COVER, SUBSTRATE, LOCATION RELATIVE TO FENCE, and HUMAN ACTIVITY. We used a zero-inflated Poisson model because our data were count-based and we had a significant number of months where we did not detect a particular focal species.

With the exception of deer, we ran each of our models twice, once with all undercrossings included and the second time after removing the underpasses. The underpasses were removed in the $2^{\text {nd }}$ suite of models because they were so fundamentally 
different in structure and dimensionality than the culverts. For deer, we only ran models with underpasses included because deer were almost solely detected at those two locations (95.7\% of detections). Significance was determined at the 0.05 level, and all data analysis was completed in JMP 13 (SAS Institute Inc., Cary, NC, USA).

\section{RESULTS}

Across our 11 sites, the cameras were active a total of exactly 15,000 survey nights. There was variance in survey effort due to battery failure, theft, or fear of theft of our cameras (Table 3.1). At the maximum, several sites were monitored continuously during our 5-year study period ( 1800 nights), and at the minimum one site was monitored for only 7 months (207 nights; Santa Margarita Creek underpass) due to theft. Across all 11 sites, we acquired 2,015 detections of our four focal species. Bobcat were most frequently detected $(n=1,231)$, followed by deer $(n=610)$, then bear $(n=142)$ and mountain lion $(\mathrm{n}=32)$.

Mountain lion were detected at 6 of 11 sites, with one site (N3.1) accounting for $46.9 \%(15 / 32)$ of all detections (Table 3.5a). Bear were detected at 8 sites (Table 3.5b), and most sites averaged 1 bear detection every 1-3 months. Deer were also detected at 8 sites (Table 3.5b), with 95\% (581/610) of deer detections occurring at the two underpasses, where they were detected once every 1-2 days on average. Deer were detected at 5 of the culverts $<5$ times each despite them being monitored for longer than the underpasses. Bobcats were detected at every site, but with considerable variation in activity between sites, ranging from only 2 detections in 4 years of monitoring (at $58 \mathrm{~N}$ ), to averaging 9 visits per month (at N3.1; Table 3.5a). 


\section{Landscape resistance}

In the models with all undercrossings included, there was no evidence for an effect of LANDSCAPE RESISTANCE on mountain lion $(p=0.411)$, or deer $(p=0.3026)$ activity, yet LANDSCAPE RESISTANCE had a negative effect on bear activity $(\mathrm{p}=0.0003)$. After removing the underpasses, there was still no evidence for an effect of LANDSCAPE RESISTANCE on mountain lion activity $(\mathrm{p}=0.250)$, and the negative effect on bear activity remained $(\mathrm{p}=0.0006)$.

\section{Dimensionality}

To avoid collinearity in our model, we removed HEIGHT and WIDTH from the analysis because they were significantly (>0.7) correlated with OPENNESS (Figure 3.2). The all-undercrossings models indicated no evidence for an effect of OPENNESS on mountain lion activity $(\mathrm{p}=0.270)$ or bear activity $(\mathrm{p}=0.062)$, but OPENNESS was positively related to deer activity $(\mathrm{p}<0.0001)$ and negatively related to bobcat activity $(\mathrm{p}<0.0001)$. In the culvert-only models, there was still no evidence for an effect of OPENNESS on mountain lion activity $(\mathrm{p}=0.176)$ or bear activity $(\mathrm{p}=0.124)$, and a positive effect on bobcat activity $(\mathrm{p}<0.0001)$. In the models with all undercrossings included there was no evidence for an effect of LENGTH on mountain lion activity $(\mathrm{p}=0.726)$ or bear activity $(\mathrm{p}=0.091)$, a negative effect on deer activity $(\mathrm{p}<0.0001)$, and a positive effect on bobcat activity $(\mathrm{p}=0.0027)$. In the culvert only models, LENGTH had a positive effect on mountain lion activity $(\mathrm{p}=0.005)$, and no evidence for an effect on bear $(\mathrm{p}=0.485)$ or bobcat $(\mathrm{p}=0.443)$ activity. 


\section{Distance to cover and substrate}

The all-undercrossings models indicated no evidence for an effect of DISTANCE TO COVER on mountain lion activity $(\mathrm{p}=0.263)$ or bear activity $(\mathrm{p}=0.887)$, a positive effect on deer activity $(\mathrm{p}<0.0001)$, and a negative effect on bobcat activity $(\mathrm{p}<0.0001)$. In the culvert only models, there was still no evidence of an effect of DISTANCE TO COVER on mountain lion activity $(\mathrm{p}=0.145)$ or bear activity $(\mathrm{p}=0.102)$, and had a negative effect on bobcat activity $(\mathrm{p}<0.0001)$.

In the all-undercrossings model, mountain lion $(\mathrm{p}=0.015)$, deer $(\mathrm{p}<0.0001)$, and bobcat $(\mathrm{p}<0.0001)$ activity was higher in undercrossings with natural substrate, while bear activity was not associated with SUBSTRATE $(\mathrm{p}=0.186)$. In the culvert only models, there was no longer evidence that SUBSTRATE was associated with mountain lion activity $(\mathrm{p}=0.595)$ or bear activity $(\mathrm{p}=0.864)$, but bobcat activity was still higher in undercrossings with natural substrate $(\mathrm{p}<0.0001)$.

\section{Fencing and human activity}

In the all-undercrossings model mountain lion $(\mathrm{p}=0.046)$, deer $(\mathrm{p}<0.0001)$, and bobcat $(\mathrm{p}<0.0001)$ activity was higher outside the wildlife exclusion fence zone, while bear activity was higher inside $(\mathrm{p}<0.0001)$. In the culvert-only models, there was no longer evidence for an effect on mountain lion activity $(\mathrm{p}=0.058)$, but there was still higher bear activity inside $(\mathrm{p}<0.0001)$, and higher bobcat activity outside $(\mathrm{p}<0.0001)$.

There was human activity at every site, but most sites on averaged $<1$ event every 2 months (Table 3.2b; Figure 3.7), while the 2 sites with the most human activity had between 1.5 and 2 human detection events per month (N3.1 and SmCk underpass). At 2 sites $(58 \mathrm{~S}$ and $58 \mathrm{~N})$ we only detected one person in $\sim 4$ years of monitoring at two sites, 
and our maximum was 60 human crossings at a site we monitored for $\sim 3$ years (N3.1). In the all-undercrossings model, there was no evidence for an effect of HUMAN ACTIVITY on mountain lion activity $(\mathrm{p}=0.415)$, bear activity $(\mathrm{p}=0.140)$, or bobcat activity $(\mathrm{p}=0.719)$, and a positive effect on deer activity $(\mathrm{p}<0.0001)$. In the culvert-only models, there was still no evidence that HUMAN ACTIVITY had an effect on mountain lion activity $(\mathrm{p}=0.231)$, bear activity $(\mathrm{p}=0.130)$, or bobcat activity $(\mathrm{p}=0.228)$.

\section{DISCUSSION}

Wildlife crossings are critical for providing connectivity across highways, especially when associated with wildlife exclusion fencing. However, the specific characteristics associated with high wildlife use are poorly known, and probably better understood for ungulates than for carnivores. We documented mule deer, black bear, mountain lion, and bobcat activity at 11 undercrossings along Highway 101 near San Luis Obispo, California for 7-61 months between 2012-17. We found significant variation between our four focal species regarding undercrossing activity and associations with various factors.

Deer

Although deer were detected at 8 of the 11 sites, they clearly used the underpasses far more than the culverts. After controlling for survey effort, there was 100x more deer activity at the 2 underpasses compared to the 9 culverts. Since our cameras were usually located in the middle of the culverts, we were unable to determine the extent that deer approached culverts but declined to enter. However, at one site (Woods), we mounted the camera at the far entrance to minimize the likelihood of human disturbance, and detected 
several events consisting of deer approaching the culvert entrance but then turning away rather than passing through the $1.8 \mathrm{~m}$ wide, $2.4 \mathrm{~m}$ high concrete box culvert. Even at the large, open, and heavily utilized Santa Margarita Creek underpass, several photo sequences suggested that the deer were hesitant to cross under the highway, perhaps due to the noise of vehicles that the deer could not see. This hesitant behavior when approaching culverts has been documented by others: in Colorado, $61 \%$ of the local mule deer population used a 3m x 3m culvert to safely cross the highway (Reed et al. 1975). Deer are migratory in this area in Colorado (Reed et al. 1975), while in our study area the deer are likely resident (Taber and Dasmann 1958). This difference in life history may explain why a large proportion of deer were willing to use the culvert in the Colorado study.

Our findings are consistent with multiple studies that have shown that deer avoid small confined culverts. Mastro et al. (2008) quantified the effect of culvert openness on mule deer activity and found that sites $>0.8$ were selected, and $<0.6$ was avoided. All of our culverts had openness ratios $<0.3$ while the underpasses had openness ratios of around 13 (Table 3.2a). Oddly, the culvert with the highest deer activity ( $\mathrm{n}=16$; Woods) had one of the lowest openness ratios (0.1), yet this may be the same individual returning over and over. In Canada, deer tended to use more open undercrossings (Clevenger and Waltho 2005), and used wildlife overpasses 4-15 times more than underpasses (Clevenger and Barrueto 2014). In an earlier study in Canada, ungulates actually selected for smaller, less open undercrossings; yet these undercrossings were significantly less noisy and further from human habitation than larger undercrossings, which likely confounded the results (Clevenger and Waltho 2000). 
The remaining significant factors (LANDSCAPE RESISTANCE, distance to COVER, within the exclusion FENCE zone, SUBSTRATE, and HUMAN ACTIVITY) could all be explained by the fact that deer almost exclusively used the 2 underpasses. The two underpasses' approaches were in areas with relatively low movement cost, higher than average distance to cover, were at the ends of the wildlife exclusion fence, had natural substrate, and average human use. Regarding distance to cover, mule deer in Canada selected for undercrossings with higher distance to cover, perhaps feeling safer with higher visibility (Clevenger and Waltho 2005).

Human activity might have an impact on deer activity, but it's almost certainly not as important as dimensionality. In Canada, human activity had a slight negative impact on deer use of culverts (Clevenger and Barrueto 2014), and in Spain, ungulates never used any passages below a railway, with human activity suggested as the primary deterrent (Rodriguez et al. 1996). Our results indicate that both humans and deer tended to avoid the smallest culverts, and overall, ungulates are probably less sensitive to human activity than most carnivores.

\section{Bear}

Overall, bear were the least discriminating of our focal species. They used one of the two underpasses and, except for the Tassajara Creek culvert, most of the remaining undercrossings at relatively similar frequencies. We never detected a bear using the Santa Margarita Creek underpass in 7 months of monitoring, which is interesting given than it seems to be an important route under the highway for mountain lion, deer, and other taxa. Bear have used this underpass in the past (Perrine and Snyder 2011), thus it is possible 
(and maybe likely) that we would have detected bear there if we had monitored for longer given they are moderately infrequently detected.

The only factor that was significant in both suites of models was whether the undercrossing was inside the wildlife exclusion fence zone; bear activity was higher at sites within the wildlife fence zone. Considering that the wildlife exclusion fence zone was constructed in part due to 5 bears being hit during a 6 week period along a $4 \mathrm{~km}$ stretch of the highway (Siepel et al. 2013), this is potentially good news. Bear using the undercrossings in the wildlife exclusion fence zone is good from a habitat connectivity as well as highway safety perspective; unfortunately, no quantification of wildlife use of undercrossings occurred prior to the fence construction (Perrine 2015).

We found no evidence for an effect of length or openness on bear activity in our models. In contrast, in Banff National Park, Canada, black bear activity was higher in longer and less open undercrossings (Clevenger and Waltho 2005, Clevenger and Barrueto 2014). This pattern conforms to evolved behavior and life history trait for black bears. The longer, more constricted crossing structures black bears tend to use most (or at least not avoid in our case) for safe passage might be explained by these species' requirements for cover and avoidance of exposed, sparsely wooded habitats (Kansas and Raines 1990, Lyons et al. 2003).

If bear are tolerant of undercrossing dimensionality and structure, then the most important factor may be habitat suitability. Bear were detected only one time at any of the 3 drive-through culverts north of the wildlife exclusion fence, strongly suggesting that these structures provide little connectivity for bear despite the size of the structures. This is perplexing, because these culverts are larger and better-lit than some of the culverts 
that bear used in the wildlife fence zone. It seems likely that bears cross the highway at grade where there is no wildlife exclusion fence and no concrete median barrier, or perhaps simply do not use this area very much. The habitat here is somewhat different than the rest of the study area to the south, being mostly open rangeland as opposed to denser oak woodland. However, landscape models identified the area near these drivethrough culverts as potentially high-connectivity habitat for bears (Thorne and Huber 2011). Having bear with GPS collars would give us insight into their movement and habitat selection near the highway.

\section{Mountain lion}

Mountain lions have large home ranges and low population densities (compared to bobcats and deer at least; Sargeant et al. 1998), so it is not surprising that there were relatively few detections $(n=32)$. $\mathrm{Ng}$ et al. (2004) detected mountain lion only once during 1 year of monitoring 17 undercrossings along $~ 50 \mathrm{~km}$ of highway in southern California.

Despite not being detected very often, mountain lions used a variety of undercrossing types: they were detected at both underpasses, a large corrugated pipe culvert, and 3 concrete box culverts (Table 3.5a). One of the concrete box culverts was

only $1.2 \mathrm{~m}$ high, while the others were $3.7 \mathrm{~m}$ and $2.1 \mathrm{~m}$ high. In the all-underpasses model, there was no evidence that dimensionality had an effect on mountain lion activity. However, in the culvert-only models, mountain lion activity was significantly higher in longer culverts. There were no drastic differences between the lengths of the culverts (Table 3.2a); most were between $38.1 \mathrm{~m}$ and $53.3 \mathrm{~m}$ long. There is relatively little literature on mountain lion use of undercrossings. In Canada, mountain lions selected for 
longer and narrower undercrossings (Clevenger and Waltho 2005), but a later study found that dimensionality did not have an effect on mountain lion activity (Clevenger and Barrueto 2014).

We expected habitat suitability to be one of the most important factors driving mountain lion use of undercrossings. Interestingly, we found no evidence for an effect of landscape resistance on mountain lion activity in undercrossings. In Southern California, mountain lions selected for woody cover over more exposed habitats (Beier et al. 1995); however, in Canada, mountain lion activity was highest at crossing structures with less vegetative cover within a $1 \mathrm{~km}$ radius (Clevenger and Barrueto 2014). Also in Southern California, mountain lions were documented traveling along riparian corridors that led into undercrossings (Beier et al. 1995). In our study, the site with the second highest detections (Wat-Dist) is part of a small stream drainage that may have facilitated mountain lion movement. It is also possible that some of these detections were repeat visits by one or a few individuals.

It is slightly surprising that mountain lion activity was evidently not associated with more cover near the entrances in either model. Mountain lions usually select forested habitat over open habitat (Koehler and Hornocker 1991), and in Southern California mountain lions selected for undercrossings with "ample woody cover" (Beier et al. 1995). Human activity did not have an impact on mountain lion activity in either model. This is not too surprising given how infrequently mountain lions were detected, but other studies have found that mountain lions actively avoid humans. For example, mountain lions in Northern California spent significantly less time at and were less likely to return to carcasses after playback of human voices versus a playback of frog chorus 
(Smith et al. 2017). In Canada, human activity had a slight negative impact on mountain lion use of crossing structures (both over and undercrossings; Clevenger and Barrueto 2014).

\section{Bobcat}

Bobcats were the only focal species to use every undercrossing, yet activity was higher at less open, longer undercrossings. This is consistent with Clevenger and Waltho's (1999) findings that most carnivores generally select less open undercrossings. However, once we removed underpasses, bobcats selected for more open culverts. It may be that bobcats do not like how exposed underpasses are, yet prefer culverts that are less confined, or other factors are influencing their patterns.

Bobcats selected undercrossings with a shorter distance to cover in both models. This is not surprising; as a mesocarnivore, bobcats generally select for the safety of cover over exposed terrain (Rodriguez et al. 1996). Ng et al. (2004) found that suitable habitat (within $250 \mathrm{~m}$ ) on either side of the undercrossing was positively related to use by bobcats; thus if we define cover as suitable habitat then the results of our study support $\mathrm{Ng}$ et al.'s (2004) findings. Bobcats were detected more often in undercrossings outside our wildlife exclusion fence in both models. If bobcats are crossing the highway in our study area on top of the road, we would expect more activity inside the fenced zone, and less outside, because bobcats can cross the road at grade outside the fenced zone. This either means bobcats do not cross the road at grade (not likely), or that the undercrossings they preferred happened to be outside the fence (more likely).

Human activity did not affect bobcat use of undercrossings in either model. Human activity and development can have negative impacts on carnivore use of 
undercrossings (Clevenger and Waltho 2000, $\mathrm{Ng}$ et al. 2004), yet bobcats are probably the most urban-adapted wild felid (Riley et al. 2010). Our undercrossings are in a relatively rural area, and may have simply not had enough human activity to impact bobcat undercrossing use.

Next steps

There are more questions we plan to explore with this data set. Given that human activity is correlated with culvert dimensions (negatively with height in particular) we are planning to examine temporal interactions between humans and wildlife. We are also interested in mesocarnivore interactions and use of undercrossings. The majority of our detections are mesocarnivores (particularly grey fox, bobcat, skunk, and opossum (Didelphis virginiana)), so it may be worthwhile to examine any spatial or temporal partitioning between these species. Putting GPS collars on mountain lion, bear, and deer in our area is a logical next step. As of this writing (spring 2018), a mountain lion collaring project is underway in the greater region containing our study area. GPS collar data will reveal further insights into how mountain lions interact with the highway in our area.

\section{Management implications}

We found that dimensionality had significant effects on deer and bobcat use of undercrossings, but not mountain lion and bear activity. Deer prefer underpasses over culverts, and bobcats seem to prefer larger culverts over smaller culverts but will also use underpasses. Surrounding habitat is probably an important factor for bear and mountain lion, and on a more local scale, for bobcat. 
Aside from a long-term wildlife crossing project in Canada (Clevenger and Barrueto 2014), we are the first study to document wildlife activity at undercrossing for at least 5 years. It is important for projects to last for this long because wildlife can take up to 4-6 years to adapt to new infrastructure (Clevenger and Huijser 2011). Our 5-year dataset provides evidence that with crossing structures, highways are impenetrable barriers to large and medium sized mammals. This is particularly important for mountain lions, whose large home ranges (up to 320 square $\mathrm{km}$ ) can be reduced by the barrier effects of roads. Further, roads are one of the biggest sources of mortality for young male mountain lions dispersing to new areas (Beier et al. 2005). Given the high degree of urbanization in some parts of California, connecting the remaining quality habitat for mountain lions (and other species with large movement needs) is critical, especially since California mountain lions are composed of separate populations (Ernest et al. 2003).

Trophic level may have an effect on what type of crossing structures are most effective for promoting connectivity. Top predators like mountain lions and black bears were not influenced by dimensionality to the same extent that deer and bobcat were. We agree with Cramer and Bissonette (2005) that bigger undercrossings are generally better, cover is probably important at the ends of undercrossings especially for prey species, and deer strongly select for larger underpasses while carnivores are more plastic. In fact, underpasses may be so different structurally from culverts that we caution researchers from pooling them in the same models in future studies. Grilo et al. (2008) suggests that managing the surrounding habitat around undercrossings may be the most cost-effective way to increase use by wildlife. If affordable, overcrossings probably provide the most 
connectivity for multiple species (Clevenger and Waltho 1999, Van Wieren and Worm 2001). 
Table 3.1: Total survey effort for each site, including monitoring time frame.

\begin{tabular}{|c|c|c|c|c|}
\hline Type & Site & Month begin & Month end & Survey Nights \\
\hline Culvert & Woods & Sep-2012 & Sep-2017 & 1746 \\
\hline Culvert & N3.1 & Sep-2012 & Oct-2015 & 1071 \\
\hline Culvert & $\mathrm{TjCk}$ & Aug-2012 & Oct-2015 & 1163 \\
\hline Culvert & Wat-Dist & Aug-2012 & Sep-2017 & 1866 \\
\hline Culvert & $58 \mathrm{~N}$ & Jan-2013 & Jul-2016 & 1301 \\
\hline Culvert & $58 \mathrm{~S}$ & Sep-2012 & Jul-2016 & 1422 \\
\hline Culvert & N8.5 & Aug-2012 & Sep-2017 & 1856 \\
\hline Culvert & N9.1 & Aug-2012 & Sep-2017 & 1849 \\
\hline Culvert & N10.0 & Aug-2012 & Sep-2017 & 1808 \\
\hline Underpass & $\mathrm{RR}$ & Jul-2012 & Jul-2014 & 711 \\
\hline Underpass & SM & Aug-2012 & $\begin{array}{c}\text { Mar-2013 } \\
\text { Total }\end{array}$ & $\begin{array}{c}207 \\
\mathbf{1 5 , 0 0 0}\end{array}$ \\
\hline
\end{tabular}


Table 3.2a: Undercrossing attributes: dimensionality and distance to cover. Openness is (width*height)/length. SB indicates the undercrossing entrance on the southbound side of the highway, NB indicates the northbound side, and Avg. is the average of the two.

\begin{tabular}{lc|cccr|rrr} 
& \multicolumn{9}{|c}{$\begin{array}{c}\text { Dimensions } \\
\text { Type }\end{array}$} & Site & $\begin{array}{r}\text { Height } \\
(\mathbf{m})\end{array}$ & $\begin{array}{c}\text { Width } \\
(\mathbf{m})\end{array}$ & $\begin{array}{c}\text { Length } \\
(\mathbf{m})\end{array}$ & Openness & SB & NB & Avg. \\
Culvert & Woods & 2.44 & 1.83 & 42.57 & 0.10 & 2.67 & 9.60 & 6.13 \\
Culvert & N3.1 & 2.69 & 2.67 & 51.21 & 0.14 & 3.35 & 2.44 & 2.90 \\
Culvert & TjCk & 2.96 & 4.02 & 49.07 & 0.24 & 5.31 & 6.86 & 6.08 \\
Culvert & Wat-Dist & 1.22 & 2.44 & 51.82 & 0.06 & 2.39 & 2.74 & 2.56 \\
Culvert & 58N & 0.99 & 1.32 & 66.22 & 0.02 & 4.60 & 9.32 & 6.96 \\
Culvert & 58S & 1.07 & 1.22 & 30.12 & 0.04 & 1.22 & 14.65 & 7.94 \\
Culvert & N8.5 & 3.57 & 3.66 & 43.97 & 0.30 & 10.67 & 2.49 & 6.58 \\
Culvert & N9.1 & 2.21 & 2.53 & 47.24 & 0.12 & 11.28 & 3.45 & 7.37 \\
Culvert & N10.0 & 3.69 & 2.52 & 38.20 & 0.24 & 22.56 & 22.56 & 22.56 \\
Underpass & RR & 9.14 & 54.86 & 38.10 & 13.17 & 22.56 & 22.56 & 22.56 \\
Underpass & SM & 6.10 & 33.53 & 15.70 & 13.02 & 22.56 & 22.56 & 22.56
\end{tabular}

Table 3.2b: Undercrossing landscape resistance, average number of human detections per month, whether or not the undercrossing is within the wildlife exclusion fence zone, and the substrate within each undercrossing. Resistance values are calculated from Thorne and Huber (2011) and higher values indicate lower connectivity.

\begin{tabular}{|c|c|c|c|c|c|c|c|}
\hline \multirow[b]{2}{*}{ Type } & \multirow[b]{2}{*}{ Site } & \multicolumn{3}{|c|}{ Landscape High Resistance } & \multicolumn{3}{|c|}{ Within } \\
\hline & & $\begin{array}{l}\text { Mtn } \\
\text { lion }\end{array}$ & Bear & Deer & $\begin{array}{l}\text { Human } \\
\text { /Month }\end{array}$ & $\begin{array}{c}\text { exclusion } \\
\text { fence? }\end{array}$ & Substrate \\
\hline Culvert & Woods & 892.30 & 881.72 & 880.89 & 0.41 & $\mathrm{~N}$ & Concrete \\
\hline Culvert & N3.1 & 886.17 & 853.34 & 846.71 & 1.62 & $\mathrm{~N}$ & Concrete \\
\hline Culvert & $\mathrm{TjCk}$ & 859.82 & 845.15 & 845.30 & 0.44 & $\mathrm{Y}$ & Sediment \\
\hline Culvert & Wat-Dist & 834.20 & 841.44 & 843.24 & 0.09 & $\mathrm{Y}$ & Concrete \\
\hline Culvert & $58 \mathrm{~N}$ & 883.79 & 851.60 & 859.89 & 0.02 & $\mathrm{Y}$ & Concrete \\
\hline Culvert & $58 \mathrm{~S}$ & 885.74 & 855.65 & 865.71 & 0.02 & $\mathrm{Y}$ & Concrete \\
\hline Culvert & N8.5 & 858.93 & 847.56 & 864.76 & 0.25 & $\mathrm{~N}$ & Sediment \\
\hline Culvert & N9.1 & 863.17 & 851.37 & 866.70 & 0.25 & $\mathrm{~N}$ & Sediment \\
\hline Culvert & N10.0 & 892.66 & 869.93 & 893.81 & 0.47 & $\mathrm{~N}$ & Concrete \\
\hline Underpass & RR & 841.82 & 840.59 & 841.13 & 0.16 & $\mathrm{~N}$ & Sediment \\
\hline Underpass & SMCk & 883.19 & 862.61 & 880.36 & 2.00 & $\mathrm{~N}$ & Sediment \\
\hline
\end{tabular}


Table 3.3: Factor effects for bobcat, mountain lion, bear, and deer models with underpasses included. The response is the monthly count of detections of each focal species. Effect is the directionality of the factor on activity, $p$ value is whether or the effect was significant, and $\beta$ is the effect size for that factor. Bold values indicate significance at the 0.05 level. Effects and beta coefficients are not listed for multi-level categorical variables, year and season. For "within fence", a positive beta indicates more use outside the wildlife exclusion fence zone. For "substrate", a positive value indicates more use on concrete substrate.

\begin{tabular}{|c|c|c|c|c|c|c|c|c|}
\hline \multirow[b]{2}{*}{$\begin{array}{l}\text { Factor } \\
\text { Year }\end{array}$} & \multicolumn{2}{|c|}{ Bobcat } & \multicolumn{2}{|c|}{ Bear } & \multicolumn{2}{|c|}{ Deer } & \multicolumn{2}{|c|}{$\begin{array}{c}\text { Mountain } \\
\text { lion }\end{array}$} \\
\hline & $\underset{<}{\mathbf{p}}$ & $\boldsymbol{\beta}$ & $\begin{array}{c}\mathbf{p} \\
0.0025\end{array}$ & $\boldsymbol{\beta}$ & $\begin{array}{c}p \\
<0.0001\end{array}$ & $\beta$ & $\underset{0.002}{p}$ & $\boldsymbol{\beta}$ \\
\hline Season & 0.253 & & $<0.0001$ & & 0.01 & & 0.399 & \\
\hline $\begin{array}{l}\text { Landscape } \\
\text { resistance }\end{array}$ & NA & NA & 0.0003 & 0.036 & 0.303 & 0.002 & 0.411 & 0.019 \\
\hline Openness & $<0.0001$ & 0.061 & 0.062 & 0.050 & $<0.0001$ & 0.397 & 0.270 & 0.073 \\
\hline Length & 0.0027 & 0.012 & 0.091 & 0.016 & $<0.0001$ & 0.108 & 0.726 & 0.011 \\
\hline $\begin{array}{l}\text { Distance to } \\
\text { cover }\end{array}$ & $<0.0001$ & 0.042 & 0.887 & 0.061 & $<0.0001$ & 0.203 & 0.263 & 0.044 \\
\hline Within fence & $<0.0001$ & 1.236 & $<0.0001$ & 1.177 & $<0.0001$ & 3.862 & 0.046 & 2.218 \\
\hline Substrate & $<0.0001$ & 0.456 & 0.186 & 0.296 & $<0.0001$ & 2.637 & 0.015 & 1.749 \\
\hline $\begin{array}{l}\text { Human } \\
\text { activity }\end{array}$ & 0.719 & 0.009 & 0.140 & 0.247 & $<0.0001$ & 0.321 & 0.415 & 0.259 \\
\hline
\end{tabular}


Table 3.4: Factor effects for bobcat, mountain lion, and bear models with underpasses removed. The response is monthly count of each focal species. Effect is the directionality of the factor on activity, $p$ value is whether or the effect was significant, and the $\beta$ is the effect size for that factor. Effects and beta coefficient not listed for multi-level categorical variables, year and season. Bold values indicate significance at the 0.05 level. For "within fence", a positive beta indicates more use outside the wildlife exclusion fence zone. For "substrate", a positive value indicates more use on concrete substrate. Deer were not included because their activity was clearly associated with the underpasses.

\begin{tabular}{l|cc|cc|cc} 
& \multicolumn{2}{c}{ Bobcat } & \multicolumn{2}{c}{ Bear } & \multicolumn{2}{c}{ Mountain lion } \\
Factor & $\mathbf{p}$ & $\boldsymbol{\beta}$ & $\mathbf{p}$ & $\boldsymbol{\beta}$ & $\mathbf{p}$ & $\boldsymbol{0}$ \\
Year & $<\mathbf{0 . 0 0 0 1}$ & & $\mathbf{0 . 0 0 3 8}$ & & $\mathbf{0 . 0 0 1}$ & \\
Season & 0.300 & & $<\mathbf{0 . 0 0 0 1}$ & & 0.243 & \\
$\begin{array}{l}\text { Landscape } \\
\text { resistance }\end{array}$ & NA & NA & $\mathbf{0 . 0 0 0 6}$ & -0.039 & 0.250 & 0.039 \\
Openness & $<\mathbf{0 . 0 0 0 1}$ & 4.016 & 0.124 & -2.08 & 0.176 & -7.095 \\
Length & 0.443 & -0.004 & 0.485 & 0.007 & $\mathbf{0 . 0 0 5}$ & 0.358 \\
$\begin{array}{l}\text { Distance } \\
\text { to cover }\end{array}$ & $<\mathbf{0 . 0 0 0 1}$ & -0.0171 & 0.102 & -0.209 & 0.145 & -0.908 \\
Within fence & $<\mathbf{0 . 0 0 0 1}$ & 1.319 & 0.058 & -1.467 & $<\mathbf{0 . 0 0 0 1}$ & -0.365 \\
Substrate & $<\mathbf{0 . 0 0 0 1}$ & 0.367 & 0.864 & 0.052 & 0.595 & -9.490 \\
$\begin{array}{l}\text { Human } \\
\text { activity }\end{array}$ & & & & & & \\
& 0.228 & 0.031 & 0.13 & -0.264 & 0.231 & 0.502
\end{tabular}


Table 3.5a: Count and activity of bobcat and mountain lion at each site. Count is the number of detection events for a given species, irrespective of group size. Activity is the count divided by the total survey days. "Act*30" is activity multiplied by 30 to estimate the number of monthly detections at each site. "“_" indicates zero activity for clarity.

\begin{tabular}{lc|ccc|ccc} 
& \multicolumn{3}{|c}{ Bobcat } & \multicolumn{3}{c}{ Mountain Lion } \\
Site & $\begin{array}{c}\text { Survey } \\
\text { nights }\end{array}$ & Count & Activity & Act.*30 & Count & Activity & Act*30 \\
Woods-Culv & 1746 & 295 & 0.169 & 5.07 & 0 & - & - \\
N3.1-Culv & 1071 & 319 & 0.298 & 8.94 & 15 & 0.014 & 0.42 \\
TjCk-Culv & 1163 & 9 & 0.008 & 0.23 & 0 & - & 0.00 \\
WatDist-Culv & 1866 & 90 & 0.048 & 1.45 & 10 & 0.005 & 0.16 \\
58N-Culv & 1301 & 2 & 0.002 & 0.05 & 0 & - & - \\
58S-Culv & 1422 & 57 & 0.040 & 1.20 & 0 & - & - \\
N8.5-Culv & 1856 & 287 & 0.155 & 4.64 & 1 & 0.001 & 0.02 \\
N9.1-Culv & 1849 & 100 & 0.054 & 1.62 & 2 & 0.001 & 0.03 \\
N10.0-Culv & 1808 & 4 & 0.002 & 0.07 & 0 & - & - \\
RR-UP & 711 & 55 & 0.077 & 2.32 & 2 & 0.003 & 0.08 \\
SM-UP & 207 & 13 & 0.063 & 1.88 & 2 & 0.010 & 0.29
\end{tabular}


Table 3.5b: Count and activity of deer and black bear at each site. Count is the number of detection events for a given species, irrespective of group size. "act." is the count divided by the total survey days. "act*30" is activity multiplied by 30 to estimate the number of monthly detections at each site. "“-“ indicates zero activity for clarity.

\begin{tabular}{lc|ccc|ccc} 
& \multicolumn{3}{|c}{ Deer } & \multicolumn{3}{c}{ Bear } \\
Site & $\begin{array}{c}\text { Survey } \\
\text { days }\end{array}$ & Count & Activity & Act*30 & Count & Activity & Act*30 \\
Woods-Culv & 1746 & 16 & 0.009 & 0.27 & 4 & 0.002 & 0.07 \\
N3.1-Culv & 1071 & 1 & 0.001 & 0.03 & 17 & 0.016 & 0.48 \\
TjCk-Culv & 1163 & 1 & 0.001 & 0.03 & 45 & 0.039 & 1.16 \\
WatDist-Culv & 1866 & 4 & 0.002 & 0.06 & 28 & 0.015 & 0.45 \\
58N-Culv & 1301 & 0 & - & - & 14 & 0.011 & 0.32 \\
58S-Culv & 1422 & 0 & - & - & 18 & 0.013 & 0.38 \\
N8.5 & 1856 & 4 & 0.002 & 0.06 & 1 & 0.001 & 0.02 \\
N9.1 & 1849 & 0 & - & - & 0 & - & - \\
N10.0 & 1808 & 3 & 0.002 & 0.05 & 0 & - & - \\
RR-UP & 711 & 343 & 0.482 & 14.47 & 15 & 0.021 & 0.63 \\
SM-UP & 207 & 238 & 1.150 & 34.49 & 0 & - & -
\end{tabular}



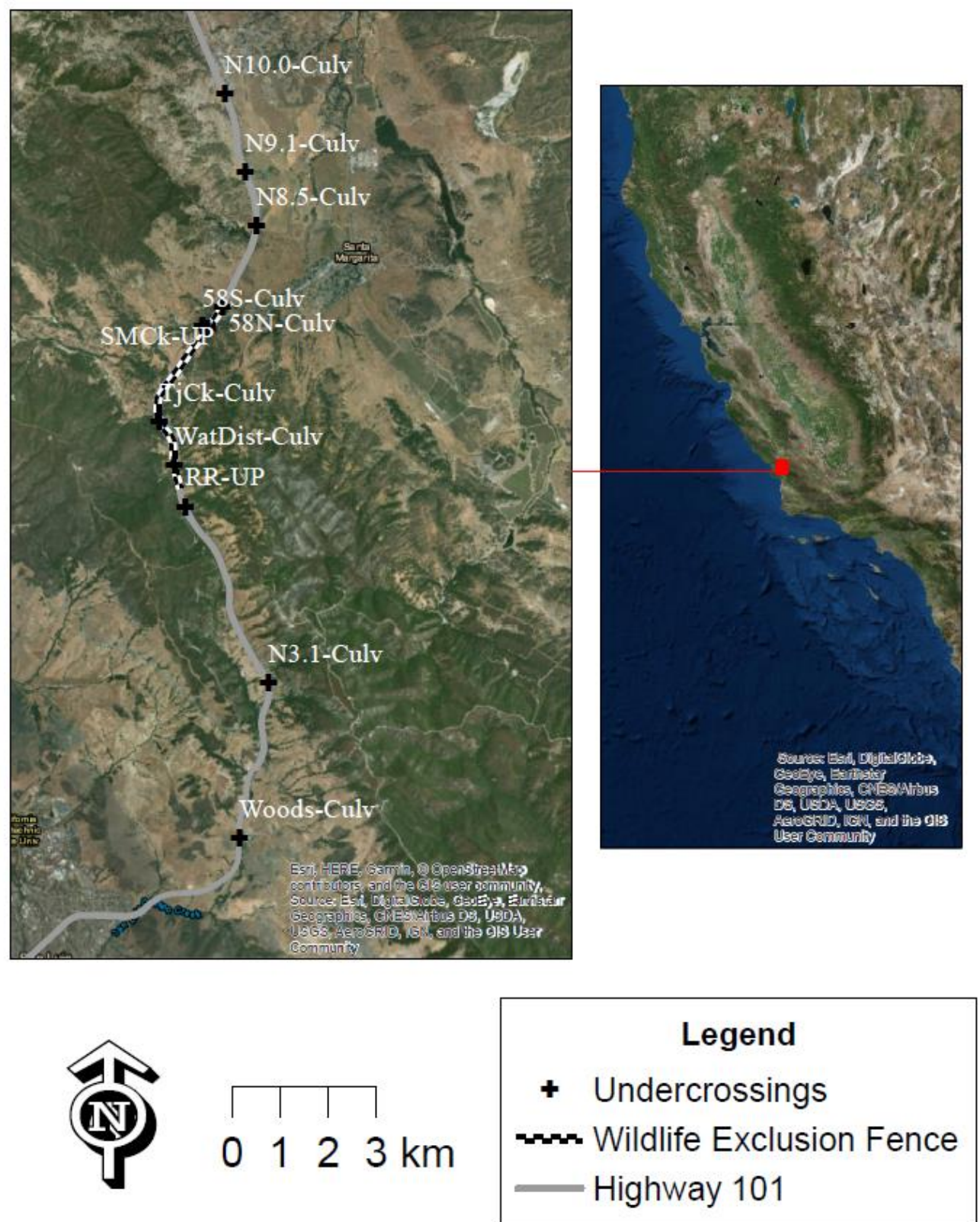

Figure 3.1: Location of undercrossings along a $19.3 \mathrm{~km}$ section of Highway 101 between San Luis Obispo and Atascadero, California, USA. The wildlife exclusion fence is $4 \mathrm{~km}$ long. 


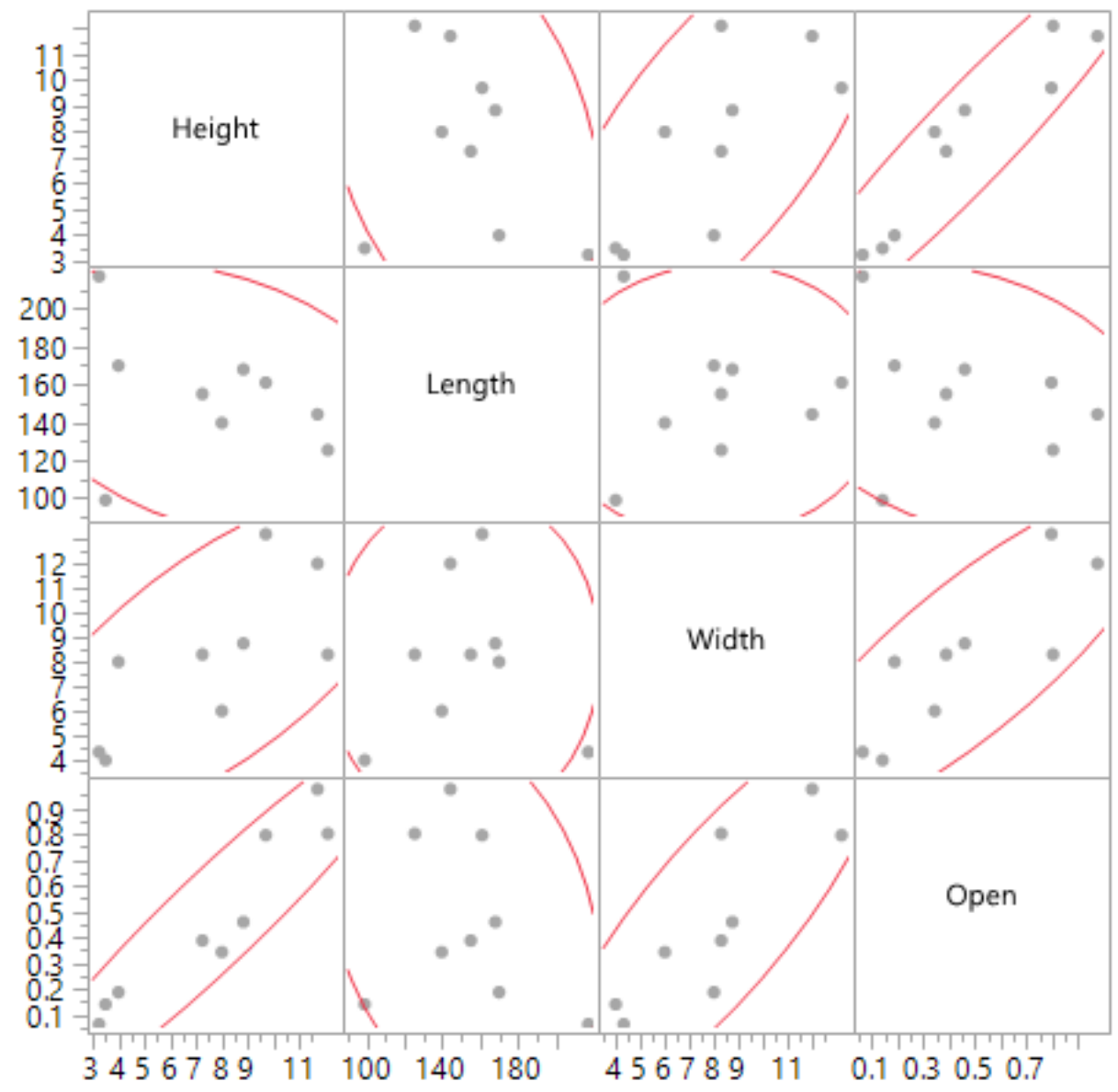

Figure 3.2: Covariance matrix between height, length, width, and openness. Height and width were highly (>0.7) correlated with openness, so height and width were not included in modeling. Open indicates the factor "OPENNESS".

\section{Dimension Correlations}

$\begin{array}{lrrrr} & \text { Height } & \text { Length } & \text { Width } & \text { Open } \\ \text { Height } & 1.0000 & -0.3095 & 0.7037 & 0.9474 \\ \text { Length } & -0.3095 & 1.0000 & 0.0293 & -0.2820 \\ \text { Width } & 0.7037 & 0.0293 & 1.0000 & 0.8332 \\ \text { Open } & 0.9474 & -0.2820 & 0.8332 & 1.0000\end{array}$




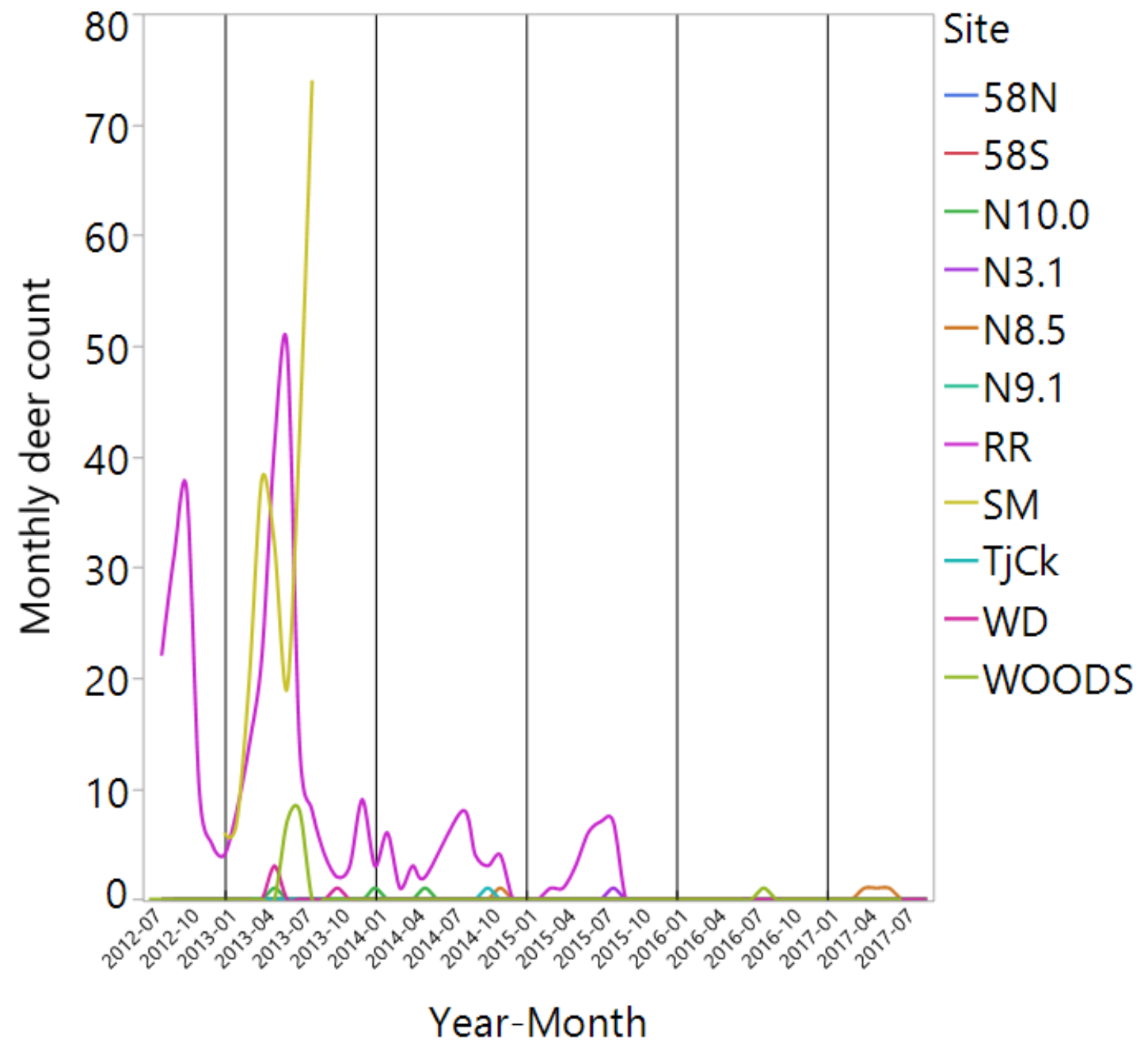

Figure 3.3: Monthly count of deer detections at each site, irrespective of group size. Deer almost exclusively used the two underpasses (RR and SM). N=610. 


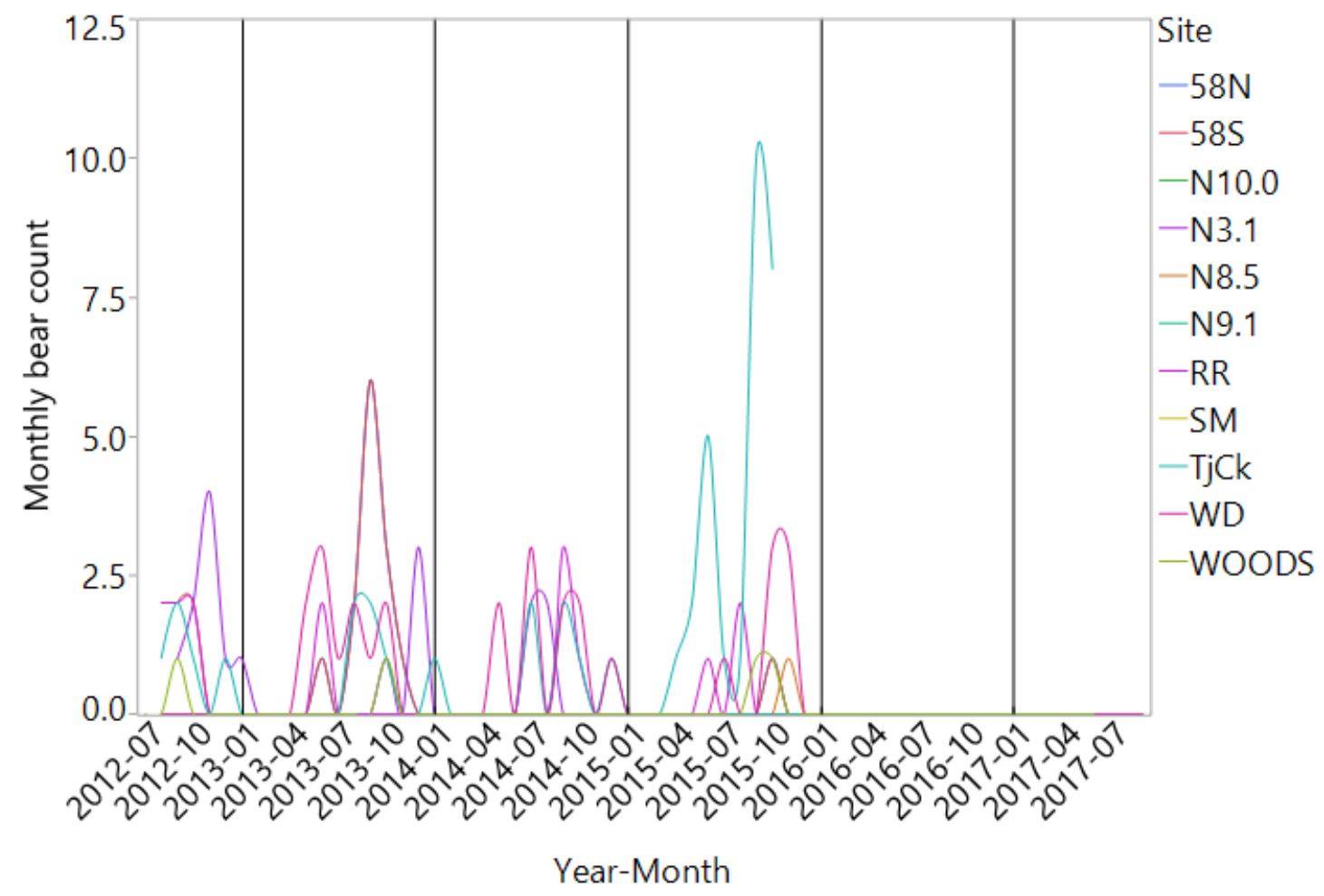

Figure 3.4: Monthly count of bear at each site, irrespective of group size. $\mathrm{N}=142$. 


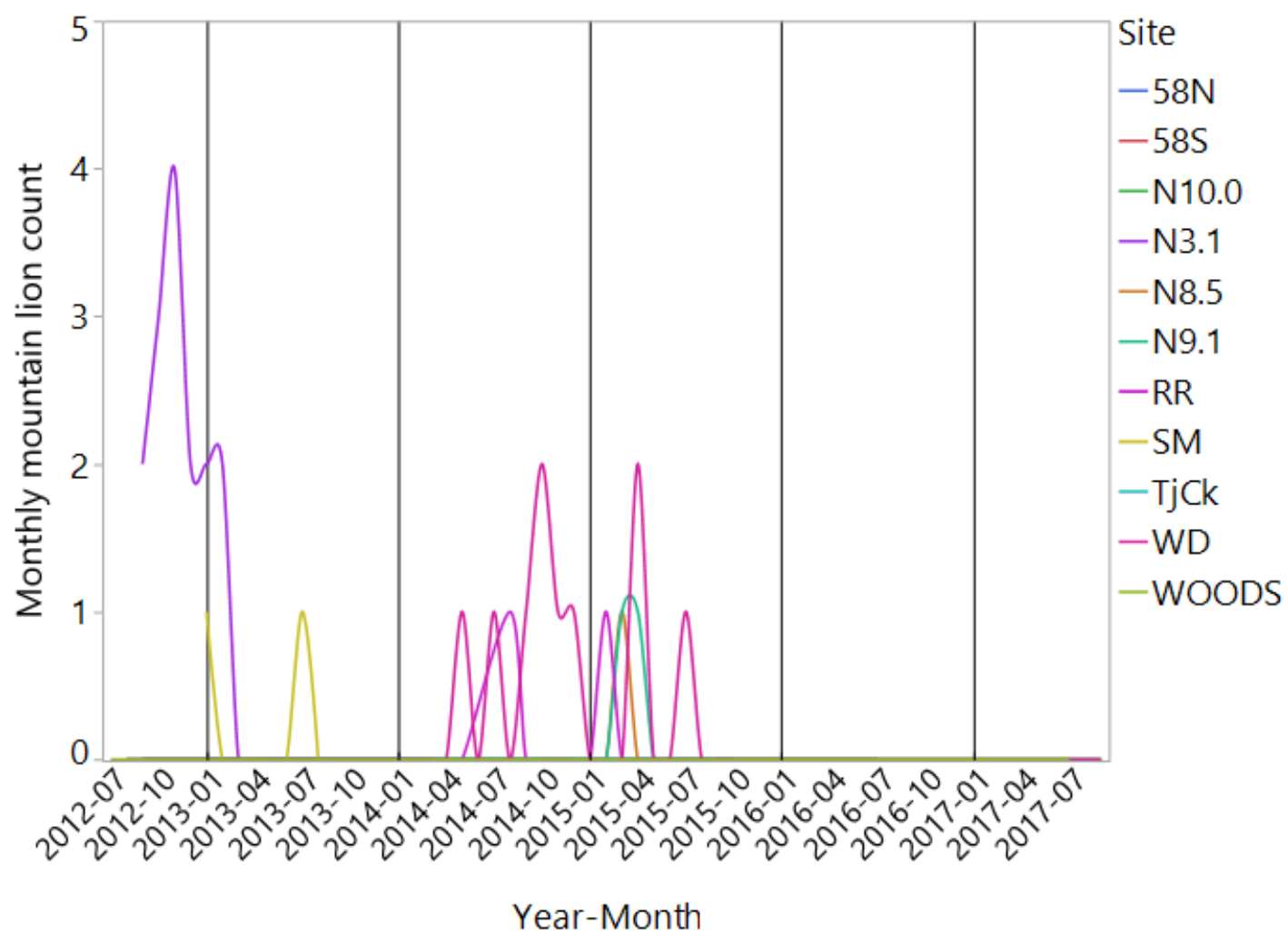

Figure 3.5: Monthly count of mountain lion at each site, irrespective of group size. $\mathrm{N}=32$. 


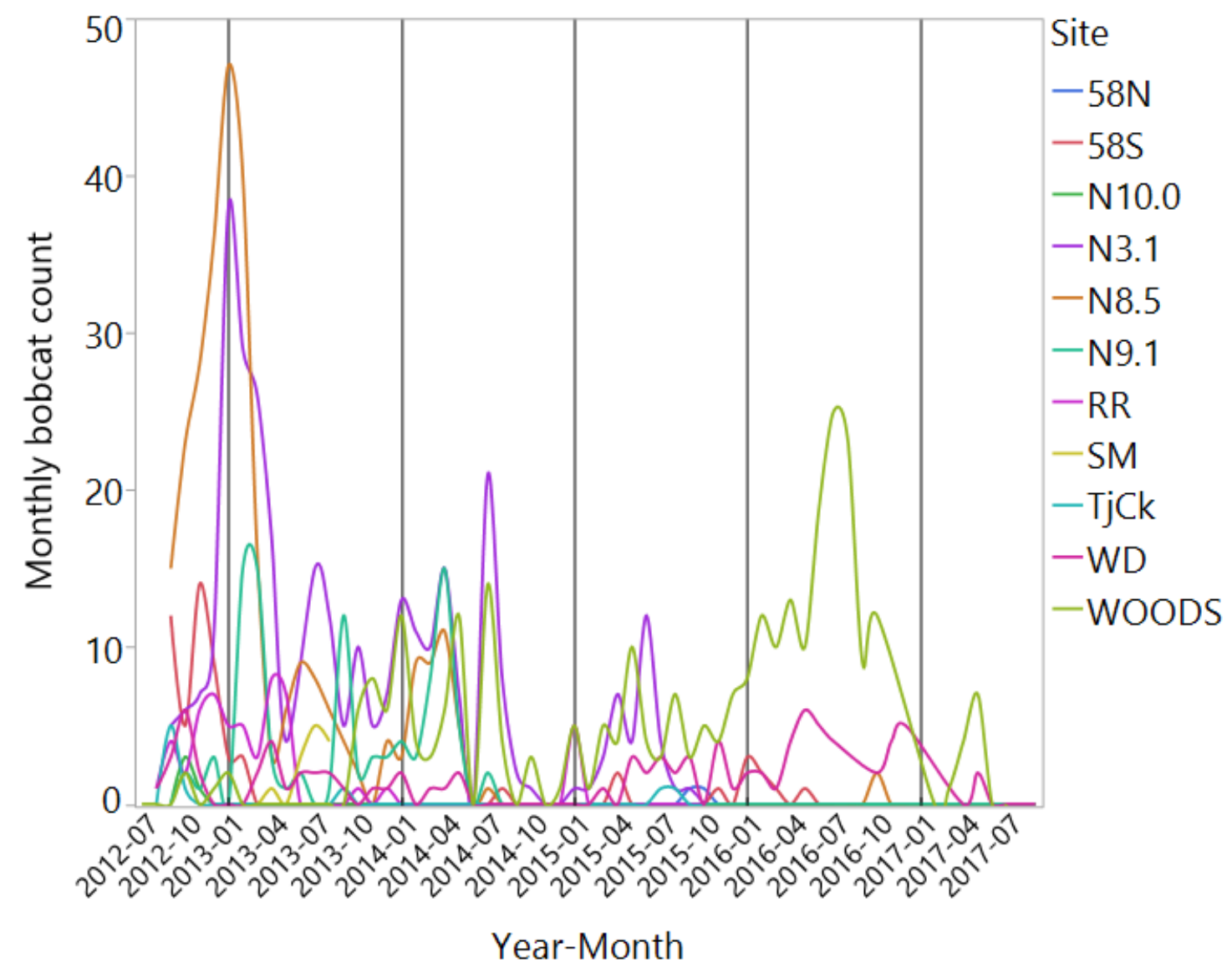

Figure 3.6: Monthly count of bobcat at each site, irrespective of group size. $\mathrm{N}=1231$. 


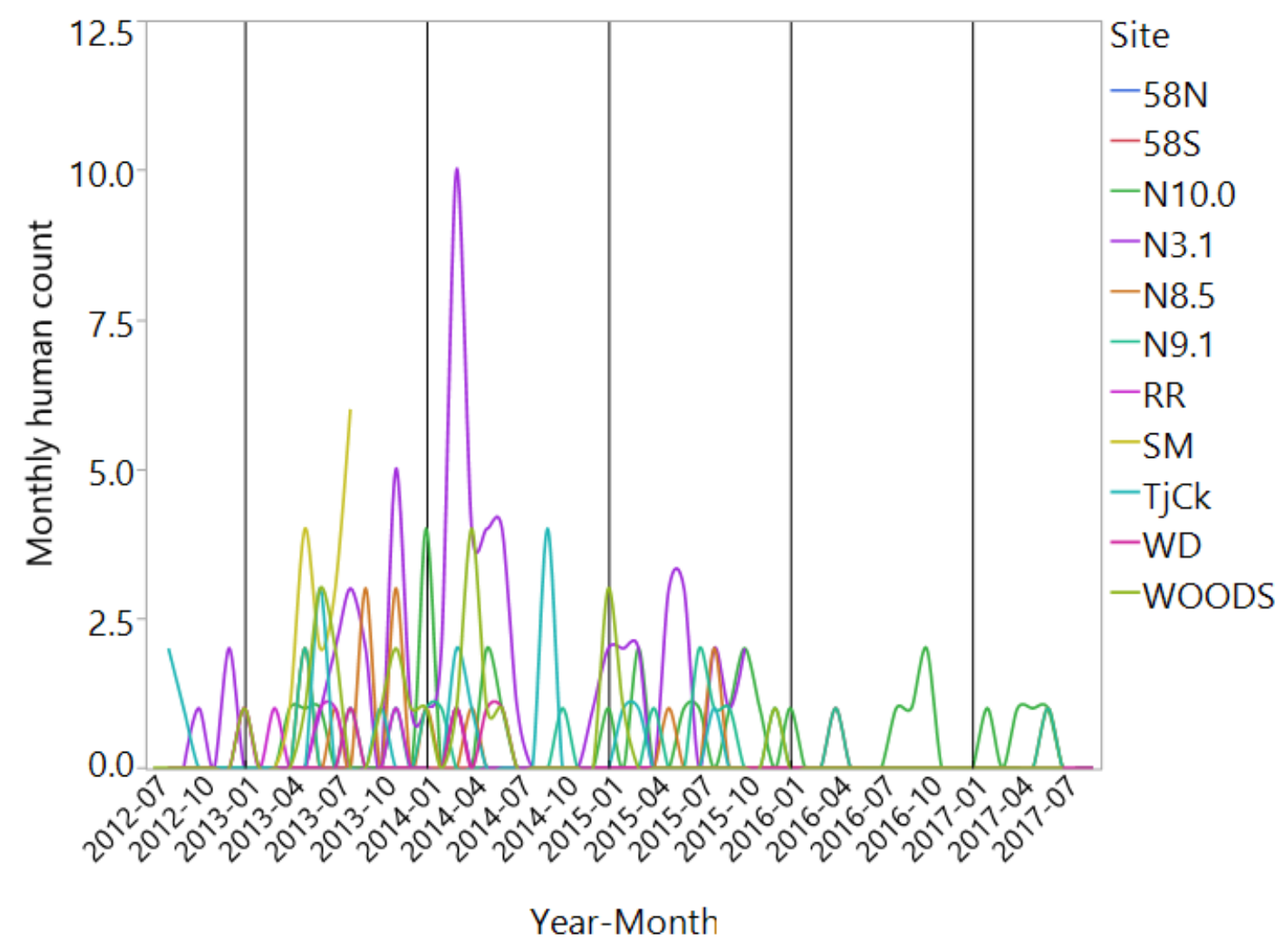

Figure 3.7: Monthly count of human at each site, irrespective of group size. $\mathrm{N}=188$. 


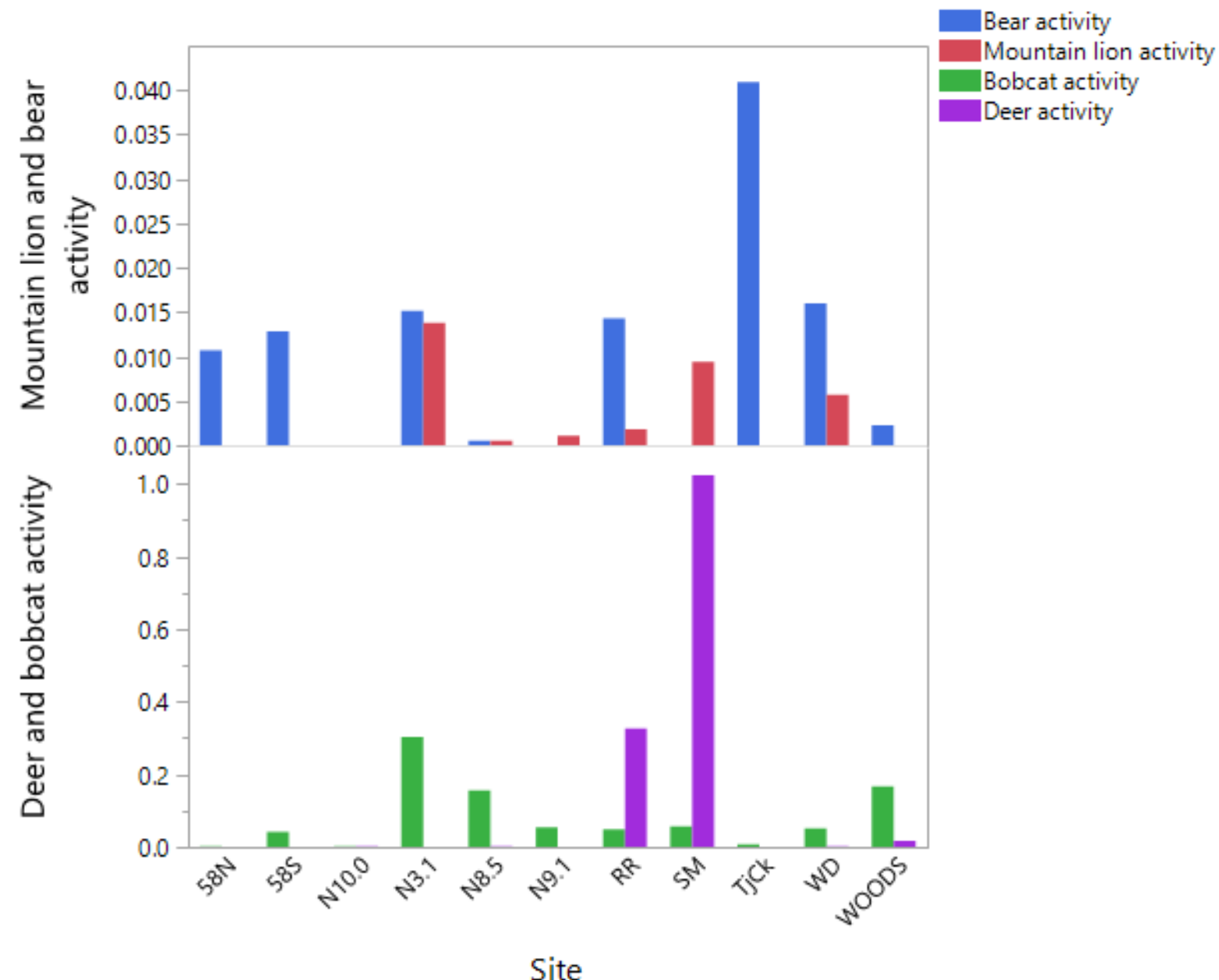

Figure 3.8: Focal species activity at each site. Bars are the average monthly count divided by 30 to give an estimate for daily activity. RR and SM are both underpasses, the rest of the sites are culverts. 


\section{REFERENCES}

Alexander, S.M., and N.M. Waters. 2000. The effects of highway transportation corridors on wildlife: a case study of Banff National Park. Transportation Research Part C: Emerging Technologies, 8: 307-320.

Allen, T.D.H., M.P. Huijser, and D.W. Willey. 2013. Effectiveness of wildlife guards at access roads. Wildlife Society Bulletin 37.2: 402-408.

Andis, A.Z., M.P. Huijser, and L. Broberg. 2017. Performance of arch-style road crossing structures from relative movement rates of large mammals. Frontiers in Ecology and Evolution 5: 122.

Arizona Department of Transportation. 2013. Wildlife escape measures. Arizona Department of Transportation, Phoenix, Arizona, USA. http://www.azdot.gov/docs/defaultsource/planning/description_of_wildlife_escape_measures.pdf?sfvrsn=2

Bangs, E.E., T.N. Bailey, and M.F. Portner. 1989. Survival rates of adult female moose on the Kenai Peninsula, Alaska. Journal of Wildlife Management 53: 557-563.

Barbour, M., T. Keeler-Wolf, and A.A. Schoenherr, editors. 2007. Terrestrial vegetation of California. University of California Press.

Bashore, T.L., W.M. Tzilkowski, and E.D. Bellis. 1985. Analysis of deer-vehicle collision sites in Pennsylvania. Journal of Wildlife Management 49: 769-774.

Beckmann, J.P., A.P. Clevenger, M.P. Huijser, and J.A. Hilty. 2010. Safe passages. Highways, wildlife, and habitat connectivity. Island Press, Washington, D.C., USA. 
Beier, P., D. Choate, and R.H. Barrett. 1995. Movement patterns of mountain lions during different behaviors. Journal of Mammalogy 76: 1056-1070.

Belovsky, G. E. 1987. Extinction models and mammalian persistence. Pages 3558 in M. E. Soulé, editor. Viable populations for conservation. Cambridge University Press, Cambridge, Massachusetts, USA.

Bissonette, J., and M. Hammer. 2000. Effectiveness of earthen return ramps in reducing big game highway mortality in Utah. UTCFWRU Report Series 2000: 1-29.

Blincoe, L., A. Seay, E. Zaloshnja, T. Miller, E. Romano, S. Luchter, and R. Spicer. 2002. The economic impact of motor vehicle crashes. U.S. Department of Transportation National Highway Traffic Safety Administration, Washington, D.C., USA.

Bliss-Ketchum, L.L., P. Cramer, S. Gregory, S. Jacobson, M. Trask, S. Wray. 2016. The effect of artificial light on wildlife use of a passage structure. Biological Conservation 199: 25-28.

Brown, J.H. 1986. Two decades of interaction between the Mac- Arthur-Wilson model and the complexities of mammalian distributions. Biological Journal of the Linnaean Society 28: 231-251.

California Department of Fish and Wildlife [CDFW]. CDFW website. Mule Deer (Odocoileus hemionus). https://www.wildlife.ca.gov/Regions/6/Deer/Natural-History. Chapman J.A. and G. Feldhamer. 1982. Wild Mammals of North America. Johns Hopkins University Press, USA. 
Chruszcz B., A.P. Clevenger, K. Gunson, and M. Gibeau. 2003. Relationships among grizzly bears, highways and habitat in the Banff-Bow Valley, Alberta, Canada. Canadian Journal of Zoology 81: 1378-1391.

Clevenger, A.P., A.T. Ford, and M.A. Sawaya. 2009. Banff wildlife crossings project: integrating science and education in restoring population connectivity across transportation corridors. Report for the Parks Canada Agency.

Clevenger, A.P., and M. Barrueto (eds). 2014. Trans-Canada highway wildlife and monitoring research, final report, part B: Research Prepared for Parks Canada Agency, Radium Hot Springs, British Columbia.

Clevenger, A.P., and M. Barrueto. 2014. Trans-Canada highway wildlife and monitoring research, final report, part B: Research Prepared for Parks Canada Agency, Radium Hot Springs, British Columbia.

Clevenger, A.P., and M.P. Huijser. 2011. Wildlife Crossing Structure Handbook Design and Evaluation in North America. Report to the Federal Highway Administration, Washington, DC, USA. No. FHWA-CFL/TD-11-003.

Clevenger, A.P., and N. Waltho. 1999. Dry drainage culvert use and design considerations for small- and medium sized mammal movement across and major transportation corridor. In: Evink, G.L., Garrett, P., Zeigler, D., Berry, J. (Eds.), Proceedings of the International Conference on Wildlife Ecology and Transportation. FLER-69-98. Florida Department of Transportation, Tallahassee, FL, pp. 263-277.

Clevenger, A.P., and N. Waltho. 2000. Factors influencing the effectiveness of wildlife underpasses in Banff National Park, Alberta, Canada. Conservation Biology 14.1: 47-56. 
Clevenger, A.P., and N. Waltho. 2005. Performance indices to identify attributes of highway crossing structures facilitating movement of large mammals. Biological Conservation 121: 453-464.

Clevenger, A.P., B. Chruszcz, and K.E. Gunson. 2001. Highway mitigation fencing reduces wildlife-vehicle collisions. Wildlife Society Bulletin 29: 646-653.

Clevenger, A.P., B. Chruszcz, K. Gunson, \& M. Brumfit. 2002. Highway mitigation monitoring: Three Sisters Parkway interchange. Report for Alberta Sustainable Resource Development, Canmore, Alberta, Canada.

Cramer, P.C., and J.A. Bissonette. 2005. Wildlife crossings in North America: the state of the science and practice. IN: Proceedings of the 2005 International Conference on Ecology and Transportation, Eds. Irwin CL, Garrett P, McDermott KP. Center for Transportation and the Environment, North Carolina State University, Raleigh, NC: pp. 442-447.

Cramer, P.C., and K.M. Portier. 2001. Modeling Florida panther movements in response to human attributes of the landscape and ecological settings. Ecological Modeling 140: 51-80.

Crooks K.R., and M.E. Soulé. 1999. Mesopredator release and avifaunal extinctions in a fragmented system. Nature 400: 563-566.

Crooks, K.R. 2002. Relative sensitivities of mammalian carnivores to habitat fragmentation. Conservation Biology 16: 488-502.

deVos, J.C., Jr ., M.R. Conover, and N.E. Headrick, editors. 2003. Mule deer conservation: issues and management strategies. Berryman Institute Press, Utah State University, Logan, USA. 
Dodd Jr., C.K., W.J. Barichivich, and L.L Smith. 2004. Effectiveness of a barrier wall and culverts in reducing wildlife mortality on a heavily traveled highway in Florida. Biological Conservation 118: 619-631.

Donaldson, B., Y. Kweon, and L.N. Lloyd. 2015. An evaluation of roadside activity and behavior of deer and black bear to determine mitigation strategies for animalvehicle collisions. No. FHWA/VTRC 16-R4. Virginia Transportation Research Council.

Ernest, H.B., W.M. Boyce, V.C. Bleich, B. May, S.J. Stiver, and S.G. Torres. 2003. Genetic structure of mountain lion (Puma concolor) populations in California. Conservation Genetics 4: 353.

Falk, N.W., H.B. Graves, and E.D. Bellis. 1978. Highway right-of-way fences as deer deter- rents. Journal of Wildlife Management 42: 646-650.

Forman, R.T. 2000. Estimate of the area affected ecologically by the road system in the United States. Conservation biology 14: 31-35.

Forman, R.T., and L.E. Alexander. 1998. Roads and their major ecological effects. Annual Review of Ecology and Systematics 29: 207-231.

Forman, R.T., and R.D. Deblinger. 2000. The ecological road-effect zone of a Massachusetts (U.S.A.) suburban highway. Conservation Biology 14: 36-46.

Forman, R.T.T., J.B. Sperling, A.P. Clevenger, V.H. Dale, L.F. France, C.R. Goldman, K. Heanue, J.A. Jones, F.J. Swanson, T. Turrentine, and T.C. Winter. 2003. Road ecology: science and solutions. Island Press, Washington, D.C., USA.

Foster, M.L., and S.R. Humphrey. 1995. Use of highway underpasses by Florida panthers and other wildlife. Wildlife Society Bulletin 23: 95-100. 
Gagnon, J.W., C.D. Loberger, S.C. Sprague, M. Priest, K. Ogren, S. Boe, E. Kombe, and R. E. Schweinsburg. 2013. Evaluation of desert bighorn sheep overpasses along US Highway 93 in Arizona, USA. Proceedings of the 2013 International Conference on Ecology and Transportation.

Gagnon, J.W., T.C. Theimer, N.L. Dodd, S. Boe, R.E. Schweinsburg. 2007. Traffic volume alters elk distribution and highway crossings in Arizona. Journal of Wildlife Management 71.7: 2318-2323.

Garbutt, H. 2009. Wildlife-vehicle mitigation on northeastern Ontario highways. Ontario Ministry of Transportation.

Glista, D.J., T.L. DeVault, and J.A. DeWoody. 2009. A review of mitigation measures for reducing wildlife mortality on roadways. Landscape and Urban Planning 91.1: 1-7.

Grilo, C., J.A. Bissonette, and M. Santos-Reis. 2008. Response of carnivores to existing highway culverts and underpasses: implications for road planning and mitigation. Biodiversity and Conservation 17: 1685-1699.

Harestad, A.S. and F.L. Bunnel. 1979. Home range and body weight-a reevaluation. Ecology 60(2): 389-402.

Harris, L.D., and J. Scheck. 1991. From implications to applications: the dispersal corridor principle applied to the conservation of biological diversity. Nature Conservation 2: $189-220$.

Hemker, T.P., F.G. Lindzey, and B.B. Ackerman. 1984. Population characteristics and movement patterns of cougars in southern Utah. Journal of Wildlife Management. 48: $1275-1284$. 
Hornocker, M.G., and H.S. Hash. 1981. Ecology of the wolverine in northwestern Montana. Canadian Journal of Zoology 59: 1286-1301.

Huijser, M.P., A.V. Kociolek, T.D.H. Allen, P. McGowen, P.C. Cramer, and M. Venner. 2015. Construction guidelines for wildlife fencing and associated escape and lateral access control measures. http://onlinepubs.trb.org/onlinepubs/nchrp/docs/NCHRP25- 25(84).

Huijser, M.P., J. Purdum, W. Camel-Means, and E. Fairbank. 2013. US 93 Postconstruction wildlife- vehicle collision and wildlife monitoring and research on the Flathead Indian Reservation between Evaro and Polson, Montana, Quarterly Report 2013-3. Report for the Montana Department of Transportation. Helena, MT.

Huijser, M.P., J.W. Duffield, A.P. Clevenger, R.J. Ament, and P.T. McGowen. 2009. Cost-benefit analyses of mitigation measures aimed at reducing collisions with large ungulates in the United States and Canada: A decision support tool. Ecology and Society,14.2 Article 15.

Huijser, M.P., P.T. McGowen, J. Fuller, J.A., Hardy, \& A. Kociolek. 2007. Wildlife-vehicle collision reduction study: Report to Congress (No. FHWA-HRT-08034).

Huijser, M.P., W. Camel-Means, E.R. Fairbank, J.P. Purdum, T.D.H. Allen, A.R. Hardy, J. Graham, J.S. Begley, P. Basting, and D. Becker. 2016. US 93 North PostConstruction Wildlife-Vehicle Collision and Wildlife Crossing Monitoring on the Flathead Indian Reservation between Evaro and Polson, Montana. Report for the Montana Department of Transportation. 
Hurlbert, S.H., 1984. Pseudoreplication and the design of ecological field experiments. Ecological Monographs 54(2): 187-211.

Jennings, M.K. 2013. Landscape dynamics in Southern California: Understanding mammalian carnivore response to fire and human development. [Ph.D. Dissertation]. University of California, Davis and San Diego State University.

Jones, M.E. 2000. Road upgrade, road mortality and remedial measures: impacts on a population of eastern quolls and Tasmanian devils. Wildlife research 27(3): 289-296.

Kansas, J.L., and R.M. Raines. 1990. Methodologies used to assess the relative importance of ecological land classification units to black bears in Banff National Park, Alberta. International Conference on Bear Research and Management 8: 155-160.

Knapp, K.K., X. Yi, T. Oakasa, W. Thimm, E. Hudson, and C. Rathmann. 2004. Deer-vehicle crash countermeasure toolbox: a decision and choice resource. Midwest Regional University Transportation Center, Madison, Wisconsin, USA.

Koehler, G.M., and M.G. Hornocker. 1991. Seasonal resource use among mountain lions, bobcats, and coyotes. Journal of Mammalogy 72: 391-396.

Kruidering, A.M., G. Veenbaas, R. Kleijberg, G.Koot, Y. Rosloot, and E. van Jaarsveld. 2005. Leidraad faunavoorzieningen bij wegen. Rijkswaterstaat, Dienst Weg-en Waterbouwkunde, Delft, The Netherlands.

Lambert, D. 1992. Zero-inflated Poisson regression, with an application to defects in manufacturing. Technometrics 34.1: 1-14.

Lee, J.S., E.W. Ruell, E.E. Boydston, L.M. Lyren, R.S. Alonso, J.L. Troyer, K.R. Crooks, and S. VandeWoude. 2012. Gene flow and pathogen transmission among 
bobcats (Lynx rufus) in a fragmented urban landscape. Molecular Ecology 21: 16171631.

Little, S.J., R.G. Harcourt, and A.P. Clevenger. 2002. Do wildlife passages act as prey traps? Biological Conservation 107: 135-145.

Loberger, C., J.S. Gagnon. M. Sprague, M. Priest and R. Schweinsburg. 2013. Evaluation of a wildlife fencing retrofit along Interstate-17: adding 1.2 meters (4') to interstate right-of-way fence reduced elk-vehicle collisions by $100 \%$. Proceedings of the 2013 International Conference on Ecology and Transportation (ICOET 2013), Phoenix, Arizona, USA.

Lyons, A.L., W.L. Gaines, and C. Servheen. 2003. Black bear resource selection in the northeast Cascades, Washington. Biological Conservation 113: 55- 62.

Maehr, D.S., E.D. Land, and J.C. Roof. 1991. Social ecology of Florida panthers. National Geographic Research Explorers 7: 414-431.

Main, M.B. and B.E. Coblentz. 1990. Sexual segregation among ungulates: a critique. Wildlife Society Bulletin 18: 204-210.

Main, M.B. and B.E. Coblentz. 1996. Sexual segregation in Rocky Mountain Mule Deer. Journal of Wildlife Management 60(3): 497-507.

Mastro, L.L., M.R. Conover, and S.N. Frey. 2008. Deer-vehicle collision prevention techniques. Human-Wildlife Conflicts 2: 80-92.

McCollister M.F., F.T. Van Manen. 2010. Effectiveness of wildlife underpass and fencing to reduce wildlife-vehicle collisions. Journal of Wildlife Management 74: 17221731. 
Meese, R. J., F.M. Shilling, and J.Quinn. 2009. Wildlife crossings guidance manual. California Department of Transportation, Sacramento.

New York State Department of Motor Vehicles Internet Office. 2006. Driver's Manual.

Ng, S., J.W. Dole, R.M. Sauvajot, S.P.D. Riley, and T.J. Valone. 2004. Use of highway undercrossing by wildlife in southern California. Biological Conservation 115: 499-507.

Noss, R. F., and A. Cooperrider. 1994. Saving nature's legacy: protecting and restoring biodiversity. Island Press, Washington, D.C., USA.

Perrine, J.D. 2015. Assessment of the wildlife-exclusion infrastructure in the Tassajara Creek Region of Highway 101 in San Luis Obispo County. California Department of Transportation.

Perrine, J.D. and S. Snyder. 2011. Documenting Wildlife Distribution and Activity along Highway 101 between San Luis Obispo and Atascadero. California Department of Transportation, contract 06A1337. 51 pages + appendices.

Poessel, S.A., C.L. Burdett, E.E. Boydston, L. M. Lyren, R. S. Alonso, R. N. Fisher, and K. R. Crooks. 2014. Roads influence movement and home ranges of a fragmentation-sensitive carnivore, the bobcat, in an urban landscape. Biological Conservation 180: 224-232.

Puglisi, M.J., J.S. Lindzey, and E.D. Bellis. 1974. Factors associated with highway mortality of white-tailed deer. Journal of Wildlife Management 799-807.

Reed, D.F., T.N. Woodard, T.M. Pojar. 1975. Behavioral response of mule deer to a highway underpass. Journal of Wildlife Management 39: 361-367. 
Riley, S. P., R. M. Sauvajot, T. K. Fuller, E. C. York, D. A. Kamradt, C. Bromley, and R. K. Wayne. 2003. Effects of urbanization and habitat fragmentation on bobcats and coyotes in southern California. Conservation Biology 17: 566-576.

Riley, S.P., J.P. Pollinger, R. M. Sauvajot, E. C. York, C. Bromley, T. K. Fuller, and R. K. Wayne. 2006. A southern California freeway is a physical and social barrier to gene flow in carnivores. Molecular Ecology 15: 1733-1741.

Riley, S.P.D., E.E. Boydston, K.R. Crooks, L.M. Lyren. 2010. Bobcats (Lynx rufus). In: Gehrt, S.D., S.P.D. Riley, B.L. Cypher (Eds.), Urban Carnivores: Ecology, Conflict, and Conservation. Johns Hopkins University Press, Baltimore, Maryland, USA, pp. $120-139$.

Ripple, W.J., J.A. Estes, R.L. Beschta, C.C. Wilmers, E.G., Ritchie, M. Hebblewhite, M., Berger, J., Elmhagen, B., Letnic, M., M.P. Nelson, and O.J. Schmitz. 2014. Status and ecological effects of the world's largest carnivores. Science $343: 1241484$.

Rodriguez, A., G. Crema, and M. Delibes. 1996. Use of non-wildlife passages across a high speed railway by terrestrial vertebrates. Journal of Applied Ecology 33: $1527-1540$.

Roemer, G.W., M.E. Gompper, and B.V. Valkenburgh. 2009. The ecological role of the mammalian mesocarnivore. BioScience 59: 165-173.

Romin, L.A., and J.A. Bissonette. 1996. Deer vehicle collisions: status of state monitoring activities and mitigation efforts. Wildlife Society Bulletin 24: 276-283. 
Rosell, C., J. Parpal, R. Campeny, S. Jove, A. Pasquina, and J. M. Velasco. 1997. Mitigation of barrier effect on linear infrastructures on wildlife. Ministry of Transportation, Public Works and Water Management, Delft, The Netherlands 367-372.

Rytwinski, T., K. Soanes, J.A. Jaeger, L. Fahrig, C.S. Findlay, J. Houlahan, R. van der Ree, E.A. van der Grift. 2016. How effective is road mitigation at reducing roadkill? A meta-analysis. PLoS One 11.11: e0166941.

Sargeant, G.A., D.H. Johnson, and W.E. Berg. 1998. Interpreting carnivore scentstation surveys. Journal of Wildlife Management 62: 1235-1245.

Shilling, F.M., and D.P. Waetjen. 2012. The Road Effect Zone GIS Model. Institute of Transportation Studies, University of California, Davis.

Siemers, J.L., K.R. Wilson, and S. Baruch-Mordo. 2015. Monitoring wildlifevehicle collisions: analysis and cost-benefit of escape ramps for deer and elk on US Highway 550. Department of Fish, Wildlife, and Conservation Biology, Colorado State University Fort Collins, Colorado, USA. Report No. CDOT-2015-05.

Siepel, N.R., J.D. Perrine, L.K. Schicker, and M. Robertson. 2013. Saving lives and training the next generation: State Route 101 wildlife corridor safety project. Proceedings of the 2013 International Conference on Ecology and Transportation (ICOET 2013).

Smith, J.A., J.P. Suraci, M. Clinchy, A. Crawford, D. Roberts, L.Y. Zanette and C.C. Wilmers, 2017. Fear of the human 'super predator' reduces feeding time in large carnivores. Proceedings of the Royal Society B, 284(1857), p. 20170433. 
Snyder, S.A. 2014. Examining the impacts of State Route 101 on wildlife using road kill surveys and remote cameras. Master's Thesis, California Polytechnic University San Luis Obispo.

Sommer, M.L., R.L. Barboza, R.A. Botta, E.B. Kleinfelter, M.E. Schauss and J.R. Thompson. 2007. Habitat guidelines for mule deer: California woodland chaparral ecoregion. Mule Deer Working Group, Western Association of Fish and Wildlife Agencies.

Sparks, J.L., J.E. Gates. 2017. Seasonal and regional animal use of drainage structures to cross under roadways. Human-Wildlife Interactions 11(2): 182-191.

Spencer, W.D., P. Beier, K. Penrod, K. Winters, C. Paulman, H. RustigianRomsos, J. Strittholt, M. Parisi, and A. Pettler. 2010. California Essential Habitat Connectivity Project: A Strategy for Conserving a Connected California. Prepared for California Department of Transportation, California Department of Fish and Game, and Federal Highways Administration.

Stickles, J.H., D.B. Stone, C.S. Evans, K.V. Miller, R.J. Warren, D.A. Osborn, and C.H. Killmaster. 2015. Using deer-vehicle collisions to map white-tailed deer breeding activity in Georgia. Journal of the Southeastern Association of Fish and Wildlife Agencies 2: 202-207.

Stoner, D. 1925. The toll of the automobile. Science 61: 56-58.

Stull, D.W., W.D. Gulsby, J.A. Martin, G.J. D'Angelo, G.R. Gallagher, D.A. Osborn, R.J. Warren, and K.V. Miller. 2011. Comparison of fencing designs for excluding deer from roadways. Human-Wildlife Interactions 5: 47-57. 
Taber, R.D. and R.F. Dasmann. 1958. The black-tailed deer of the chaparral: its life history and management in the North Coast Range of California (No. 8). California Department of Fish and Game, Game Management Branch, Sacramento, California.

Thorne, J., and P. Huber. 2011. GIS modeling of landscape permeability for wildlife on the Highway 101 corridor between San Luis Obispo and Atascadero. Final project report to California Department of Transportation.

Thorne, J., D. Cameron, V. Jignour. 2002. Wildlands Conservation in the Central Coast region of California. Report to the California Wilderness Coalition.

Thorne, J.H., D. Cameron, and J.F. Quinn. 2006. A conservation design for the central coast of California and the evaluation of mountain lion as an umbrella species. Natural Areas Journal 26: 137-148.

Van der Zee, F. F., J. Wiertz, C.J. Ter Braak, R.C. Apeldoorn. 1992. Landscape change as a possible cause of the badger Meles meles L. decline in the Netherlands. Biological Conservation 61.1: 17-22.

Van Dyke F.G, R.H. Brocke, and H.G. Shaw. 1986. Use of road track counts as indices of mountain lion presence. Journal of Wildlife Management 50: 102-109. Van Wieren, S.E., and P.B. Worm. 2001. The use of a motorway wildlife overpass by large mammals. Netherlands Journal of Zoology 51: 97-105.

Yanes, M., J. M. Velasco, and F. Suarez. 1995. Permeability of roads and railways to vertebrates: the importance of culverts. Biological Conservation 71: 217-222. 